ECONOMIC GROWTH CENTER

YALE UNIVERSITY

P.O. Box 208269

New Haven, CT 06520-8269

http://www.econ.yale.edu/ egcenter/

CENTER DISCUSSION PAPER NO. 874

\title{
PATHS TO SUCCESS: THE RELATIONSHIP BETWEEN HUMAN DEVELOPMENT AND ECONOMIC GROWTH
}

\author{
Michael Boozer \\ Yale University \\ Gustav Ranis \\ Yale University \\ Frances Stewart \\ University of Oxford \\ Tavneet Suri \\ Yale University
}

December 2003

Notes: Center Discussion Papers are preliminary materials circulated to stimulate discussions and critical comments.

We thank T.N. Srinivasan, T. Paul Schultz, and participants of the Yale Trade and Development seminar for valuable comments.

Michael Boozer is at the Department of Economics and the Yale Center for International and Area Studies, Yale University. Gustav Ranis is Professor of International Economics and the Director of the Center for International and Area Studies, Yale University. Frances Stewart is Professor of Development Economics and the Director of Queen Elizabeth House, University of Oxford. Tavneet Suri is at the Department of Economics, Yale University.

This paper can be downloaded without charge from the Social Science Research Network electronic library at: http://ssrn.com/abstract=487469

An index to papers in the Economic Growth Center Discussion Paper Series is located at: http://www.econ.yale.edu/ egcenter/research.htm 


\title{
Paths to Success: The Relationship Between Human Development and Economic Growth
}

\author{
Michael Boozer \\ Gustav Ranis \\ Frances Stewart \\ Tavneet Suri
}

\begin{abstract}
This paper explores the two-way relationships between Economic Growth (EG) and Human Development (HD), building on an earlier work by Ranis, Stewart, and Ramirez (2000). Here, we show that HD is not only a product of EG but also an important input to it. The paper develops new empirical strategies to estimate the strength of the two-way chains connecting HD and EG. Building on existing growth literature, we explore the empirical determinants of positive growth trajectories running from HD to EG and find that HD plays an essential role in explaining growth trajectories. Our findings point to the empirical relevance of endogenous growth models in general, and threshold effect models in particular. We also develop a measure of the strength of the EG to HD relationship and explore some of its empirical determinants. A strong sequencing implication of our findings is that HD must be given priority for the achievement of both higher EG as well as HD.
\end{abstract}

Keyword: Human Development, Economic Growth, Threshold Models

JEL codes: O15, O57, C23 


\section{Introduction}

Since Human Development (HD), which has been defined as enlarging people's choices in a way which enables them to lead longer, healthier and fuller lives, has come to the fore as a fundamental objective of development $^{3}$, its relationship to Economic Growth (EG) has become a central issue. This is not just a matter of how the two relate at a particular point in time, but also addressed the question of sequencing over time, which has major relevance to policy. This paper explores these two issues theoretically as well as empirically. It takes off from previous work by Ranis, Stewart and Ramirez (2000) (henceforth RSR) who provided an initial exploration of the two-way relationship between HD and EG.

There are two strands of the literature on economic development that are relevant here but have tended to remain rather distinct. The predominant one has been concerned with the determinants of EG, going back to classical times, extending to neo-classical growth models and, more recently, the "new growth theory" models. The second strand asks what the ultimate objective of economic development is and how to measure it, including a discussion of the determinants of HD. We take the position that a long and healthy life represents the "bottom line" objective of human activity, even though this issue continues to be contested. ${ }^{4}$

While both literatures have acknowledged the contribution of the other - e.g. human capital is generally regarded as an important input into EG, and EG as providing the resources to achieve HD, the cumulative intertemporal interaction between the two has been generally neglected. If HD is not only an end product of the development process but also a means to generating future EG, the conventional view of a uni-directional path is mis-specified. We contend that neither EG nor HD can be analyzed in isolation of the other if one wants to understand how an economy got to its current state and where it is going. This dual causation between HD and EG was first explored empirically by RSR. They defined the loop connecting EG to HD and back again as two chains - Chain A running from EG to HD and Chain B running from HD to EG. They also attempted to identify the main component links making up

${ }^{3}$ See Sen (1992) and Sugden (1993) for a statement and review of the issues in this debate. The $H u-$ manDevelopment Reports of the UNDP present the Human Development Index (HDI) which is commonly used to summarize some aspects of HD (health, education, etc.) into a scalar measure analogous to that for EG.

${ }^{4}$ For a brief introduction to this debate, see the papers by Srinivasan (1994), Aturupane, Glewwe, and Isenman (1994), and Streeten (1994). 
each chain and their relative strengths. Exploring country behavior over time, they also came to some preliminary conclusions on the sequencing necessary for success in economic and human development.

This paper uses the analysis and findings of RSR as a point of departure to pull together the two literatures mentioned above. It extends it in two major dimensions: first, it relates the two-way relationship to contemporary growth theory; and, secondly, it develops empirical methods to assess the strengths of the two chains mentioned above which helps illuminate the sequencing issue. We also discuss how contributions to the endogenous growth literature, particularly those that focus on threshold externalities, can explain both the long-run patterns observed by RSR between countries, as well as the time paths for EG and HD within countries. Our empirical framework does not allow us to pinpoint a particular theoretical structure among this class of models, but it illustrates the compatibility between the empirical work of RSR on the sequencing priority of HD levels and threshold models that view aspects of HD as necessary preconditions for the acceleration of EG.

The paper is structured as follows: in Section Two we review and update the evidence from RSR. In Section Three we review the relevant theoretical development and growth literature. Section Four develops a measure of the strength of Chain B, as represented by the growth trajectory for each country and relates this to various measures of HD. Section Five presents a country-specific measure of the overall strength of Chain A and explores its determinants. Section Six considers the interaction of the two chains over time and explores the fundamental sequencing issue. Section Seven concludes.

\section{Summary and Update of Previous Findings}

We first review and update the evidence and concepts in RSR on which this paper builds. We interpret HD as consisting of the health, nutrition and education levels of the population. Figure 1 provides the schematic diagram of the various links in Chain A that connects EG to HD and Chain B that connects HD to EG. Chain A shows how GDP is allocated to governments and households and how these agents in turn decide how much of their resources are spent on items that are likely to promote HD, such as basic education, water, food, primary health care, etc. It also includes resources allocated by households or governments to NGOs promoting HD. While EG is thus an important element in improving HD, the relationship is not automatic but depends on the distribution of income and the propensities of 
households and governments to prioritize HD in their expenditures. The HD outcome also depends on how efficiently these inputs are deployed, which is represented by the Human Development Improvement Function. HD levels largely determine the quality of labor and the population's innovative capacity, and Chain B shows how this consequently feeds back into promoting EG, in combination with foreign and domestic investment, technology, and the policy environment, among other factors. HD is thus an important element in promoting EG, but the translation into growth is again not automatic, depending on many other elements. In principle, each country has its own Chain A and Chain B, with links of varying strength, depending on the country's initial conditions, the changing environment and policy decisions. $^{5}$

\section{INSERT FIGURE 1}

As RSR discuss, the feedbacks inherent in Figure 1 imply that a variety of outcomes is possible for a given country. Countries with strong overall chains in both directions can ride the feedback effects to achieve either a state of high EG / high HD improvements, termed the 'virtuous cycle', or they may find themselves trapped in a state of low EG / low HD improvements, termed the 'vicious cycle'. Countries that have a strong Chain A but a weak Chain B will find themselves in a comparatively 'HD-lopsided' state, and countries with the reverse pattern will find themselves in an 'EG-lopsided' state.

Adopting the RSR approach, we extend their analysis for our sample of developing countries over the period from 1960 to 2001 . There are a variety of ways of measuring an economy's level and change in HD. One, of course, is the HDI of the Human Development Reports, but this is a composite measure including a modified income indicator, which, for our purposes, confuses the issue. In our empirical work we use the infant mortality rate (IMR), which is a generally accurate indicator sensitive to change but obviously only captures one dimension of the well-being of part of the population. Hence we also look at life expectancy, literacy and enrollment rates. Following the UNDP's procedure, these indicators are

\footnotetext{
${ }^{5}$ In terms of the implications for an econometric model, this would imply that the strength of specific
} links would be heterogeneous across countries, as well as across stages of development for a given country. To tackle this problem head-on would require lengthy time series data for each country on the links of interest as well as the HD and EG variables. Since such data do not exist for any but a handful of countries, we do not attempt it in this paper. However, a useful companion exercise to the one here would be to use the 'typology' approach discussed in Ranis (1984) that uses case studies as a complement to homogeneous econometric approaches. Purely statistical approaches to this type of problem are explored in Pesaran and Smith (1995) and Durlauf and Johnson (1995). 
assessed in relation to the world's best performers, i.e. rates of change are expressed as shortfall (or gap) reductions. Using shortfall reductions helps account for 'ceiling effects' for countries near the current boundaries, for example, 3 per 1,000 for infant mortality and 85 years of age for life expectancy. ${ }^{6}$ As countries near the boundary, the actual change in the HD measure may be small. However, using the fraction of the remaining gap from the current limit can compensate for this boundary effect. ${ }^{7}$

Using the Infant Mortality Shortfall Reduction (IMSR) as the measure of HD improvement and per capita real income growth as the measure of EG, we can divide the HD/EG plane into the four quadrants of virtuous, vicious, HD-lopsided, and EG-lopsided, according to whether performance is above or below average, where the averages are those of the total sample of developing countries, weighted by population. This is illustrated in Figure 2. It is striking that the lower-right EG-lopsided quadrant is virtually empty, suggesting that the EG-lopsided outcome is not stable in the long run. All the developing countries with high growth over this period also have above average improvements in HD. On the other hand, countries appear to be able to achieve large increases in HD without necessarily being precluded from doing so by having low EG. These are the HD-lopsided countries in the upper-left panel of the graph, and are dominantly in Latin America and the Middle East. The sub-Saharan African and South Asian countries dominate the vicious cycle quadrant, and the East Asian countries dominate the virtuous cycle quadrant. The overall positive correlation between HD improvements and EG is consistent with the conventional view that $\mathrm{EG}$ is an important contributor to HD improvements, and the near absence of countries in the EG-lopsided state suggests that HD improvements are essential for achieving EG.

\section{INSERT FIGURE 2}

Figure 2 captures only the long-run cross-sectional patterns in HD and EG. It says nothing of the paths taken by individual countries over the period. To examine the issue of sequencing in more detail, in Figure 3 we plot the time paths for each country decade-by-decade for 1960-2001. This diagram captures the quadrant-to-quadrant movements of each country in direction, but not in magnitude. We

${ }^{6}$ While the shortfall reduction is a standard measure in the literature, we recognize that the presence of measurement error can be exaggerated by the use of the shortfall as values near the boundary.

${ }^{7}$ For example, if the underlying process is logistic, the shortfall reduction comes close to converting the logistic path into one of nearly constant slope. Whereas the slope of the logistic curve goes to zero as it approaches its upper or lower limit, the shortfall reduction is based only on the remaining gap to the boundary. For this reason the shortfall reduction in HD can be large even as the actual change in HD goes to zero as it approaches its boundary. 
present the same information for each country in Table 1 . Both Figure 3 and Table 1 show a strong tendency for countries in the vicious cycle to remain there, with only 5 countries that were in the vicious quadrant in the 1960's exiting it by the end of the sample period, 4 into HD-lopsided and 1 into EGlopsided. In the 1980s, many of the Latin American countries slipped from the virtuous quadrant into the HD-lopsided quadrant, possibly owing to the debt crisis. In contrast to each of the other quadrants, none of the countries remained in the EG-lopsided quadrant for the duration of the sample period. The vast majority of the countries that initially occupied this quadrant slipped back into the vicious cycle quadrant. Only one country (Oman) took the route of transiting from EG-lopsided to vicious and finally to virtuous. No other country was able to achieve high EG without first upgrading its HD. Thus, this evidence supports the RSR findings that the EG-lopsided state is not a stable outcome in the long run, which also has sequencing implications, i.e. the need for prior HD improvements to achieve above average improvements in EG.

\section{INSERT FIGURE 3}

\section{INSERT TABLE 1}

Tables 2 and 3 indicate the empirical relationships underlying Chains $A$ and B. It should be noted that some variables probably relevant to the links in the two Chains are excluded because they are not observable in the standard sources of data, though there is better coverage on the Chain B links. For this reason, our sample sizes change as we alter the regression specifications.

Table 2 explores the links in Chain A, using the Infant Mortality Shortfall Reduction (IMSR) as the measure of the change in HD. As expected, the basic relationship between EG and improvements in HD is significant in all cases except when we include a measure of poverty. Note that this is because EG and poverty are highly correlated (on the order of 0.6 ). We should also note that the relationships shown are much stronger if regional differences are not accounted for. ${ }^{8}$ The educational variables are almost invariably significant, both in terms of enrollment and public expenditure shares. Note that the gross primary enrollment and gross female primary enrollment rates are very highly correlated (0.8), which is why we opt for using just the latter. This multicollinearity is well illustrated in columns (1) through (3). Inequality of income distribution, measured by the Gini coefficient, is significantly negatively related

\footnotetext{
${ }^{8}$ The results without regional dummies are not included, but are available from the authors upon
} request. 
to HD improvements, as shown in column (4), but not when regional dummies are included in column (5). Note that when the Gini is included EG has no impact on HD improvements but, comparing this to column (2), this is purely due to the change in sample composition. Column (6) shows the significance of the share of public expenditure on health, while columns (7) and (8) explore the relationship between HD changes and poverty levels. Regional dummies underscore the relatively poor performance of Africa in achieving HD, for reasons beyond the variables deployed here: one reason is surely the impact of AIDS during the last decade. This evidence for Chain A squares with the view that EG is instrumental for HD, but its connection is strengthened once other Chain A links such as HD expenditure shares and female educational opportunities are included.

\section{INSERT TABLE 2}

Analogously, Table 3 explores Chain B relationships. These include HD levels as well as changes as explanations of EG, plus the familiar cross-country determinants of EG that have dominated the empirical growth literature for the past 20 years (see Levine and Renelt (1992) for robustness analysis). Here we see evidence for two relationships familiar from that literature: (i) a robust, positive effect of the domestic investment rate and (ii) the (conditional) convergence effect implied by the negative coefficient on initial GDP per capita. However, we also see the strong impact of initial HD levels - here captured by the inclusion of initial life expectancy or early literacy levels. The literacy rate variable has roughly the same degree of statistical correlation with EG as life expectancy. The extent of inequality as measured by the Gini coefficient is inversely related to EG but not significantly so. Similarly, HD changes also have significant impacts on EG, as shown in columns (6) and (7). The poverty head count ratio is significantly inversely related to EG, though the direction of causality here remains an issue. In the Chain B case, only Asia does significantly better than Africa according to the regional dummies. Overall, Table 3 supports the view that initial HD levels strongly affect subsequent EG performance, in addition to other determinants of growth.

\section{INSERT TABLE 3}

The evidence in this section thus supports the earlier findings of RSR in two important respects that stand in contrast to the conventional view in the literature, namely that (i) HD improvements and EG tend to move in tandem over the long run, with evidence of mutual interaction and (ii) increases in a country's EG can be sustained only if HD levels were first upgraded. This implies that only via strong 
HD can the virtuous cycle be attained. Direct attempts to strengthen EG without first enhancing HD can, at best, lead to temporary increases in EG, with a relapse into a vicious cycle. This contradicts the neoclassical view that inputs into the growth process are always substitutable. It also contrasts with the conventional view that perceives HD more as a product of growth than as an input. Figures 3 and Table 1 indicate the need for a framework that will permit us to examine the sequencing issue more precisely. This will require us to explore what is needed for a particular country to move from a vicious to a virtuous cycle over time.

\section{Growth Paths, Threshold Effects, and Human Development}

This section discusses briefly the relevant literature on human development and economic growth and the relationship of this paper to that literature. As mentioned earlier, our work is relevant to two literatures, one to the debate regarding the ultimate objective of economic activity and the role of EG in achieving it, and the second to the determinants of EG. These two literatures have generally remained separate. This section clearly illustrates the links between the two and how the views of these two literatures on the roles of HD and EG relate to our empirical analysis.

Much of the literature on HD has focused on what the appropriate measures of economic development are and whether EG or per capita income levels are sufficient as measures of the well-being of a population. While it is generally accepted that EG provides the means by which an economy can upgrade its HD levels, the HD literature questions whether EG is sufficient as a measure of development. There is no doubt that EG expands a country's choice set, but the issue still remains of how to assess the ultimate objective of economic development. ${ }^{9}$ This debate has overshadowed a careful analysis of the linkages joining HD and EG. For the most part, the HD literature specifies a unidirectional path from EG into improved HD outcomes. But, if HD is not only an end-product of the development process, but also a means to future EG, then such a unidirectional view leads to a mis-specification of the relationship.

In comparison, the literature on EG is vast. While, until recently, much of it has followed the neoclassical growth model of Solow (1956), the notion that HD is not just an outcome of the EG allocation process but serves as an input as well, is not new. From Lewis (1955) to more recent work on endogenous

\footnotetext{
${ }^{9}$ See Sen (1992) and Sugden (1993) for more detail on this debate.
} 
growth theory, human capital has been given a significant role in the determination of EG, in terms of education, health and nutrition.

In his discussion of prioritizing educational expenditures, Lewis (1955) acknowledges that "the difficulty that education raises is that it is both a consumer and an investment service". Bowman and Anderson (1963) try to disentangle the future productivity role of education from its current consumption role empirically by analyzing various leads and lags of education measures and national income. They also provide some of the first evidence that the payoff to literacy may exhibit threshold effects dependent on the fraction of an economy that is literate. Uzawa (1965) considers a broader view of HD where he takes the factor multiplying the production function, $A$, as reproducible and no longer 'exogenous' as in the neoclassical model. Whereas later authors such as Romer (1986, 1990) narrowed their definition of $A$ to be R\&D, 'ideas', etc., Uzawa's initial model was more in line with our paper by viewing $A$ as the "various activities in the form of education, health, construction and maintenance of public goods, etc., which result in an improvement of labor efficiency". This framework was later modified by Lucas (1988) who instead assumed a linear production technology for $A$, in which case growth rates need not go to zero in finite time. Lucas' reflections on the alternative sources of sustained growth from 1960 era models showed how countries could grow at different rates indefinitely, depending on their human capital. Whether it was the changes or the stocks of human capital depended on the precise mechanism used to model the endogenous growth process.

The analysis of this paper is certainly compatible with the overall message of the endogenous growth literature. However, the majority of these models fail to capture some fundamental elements of our empirical work. One flaw is that the literature often models elements of HD more as consumption goods rather than as causal factors determining future growth. This is simply a modeling issue, in that including HD both as cause and as a result of EG leads to ill-behaved (e.g. unbounded) dynamic properties of the equilibrium paths unless sufficient restrictions are placed on the model parameters. This is not a serious shortcoming of the theoretical models per se, but it is a problem for the empirical work to disentangle causation from association. A far more serious shortcoming of the Uzawa-Lucas type endogenous growth models is that they cannot account for the non-linearities in the growth paths that we saw in Figure 3. Lucas (1988) considered models which could explain permanent differences in growth rates across countries. Such models account for purely cross-sectional patterns, like those in Figure 2. But this class 
of endogenous growth models cannot explain how a given country can go from a low-EG state to a highEG state over time. To model this phenomenon we need to turn to the class of threshold-externality models as proposed by Azariadis and Drazen (1990). Their model is similar to the Lucas framework, except that around the 'critical mass' threshold for a given level of education, the other inputs are not smoothly substitutable for education. A minimum level of education must therefore be attained before an economy can escape from a low-level development trap - analogous to the vicious cycle of RSR. Thus, while the Uzawa-Lucas models focus on explaining purely cross-sectional differences in growth rates, Azariadis and Drazen go a step further to explain permanent shifts in growth rates within countries.

Note that the Azariadis-Drazen framework is not entirely 'new'. Like its contemporary counterpart, Murphy, Shleifer, and Vishny (1989), it is a version of the 'Big Push' ideas of Rosenstein-Rodan (1943) and Nurkse (1953) who note that an economy can remain stuck in an underdeveloped state unless there is a coordinated large investment effort. Hirschman (1958) critiqued this ‘balanced growth' view by arguing that the unbalancing across sectors of an economy is what pulls or pushes an economy upward and Rostow (1960) suggested distinct stages of economic growth, but focused more on the univariate characteristics of EG as opposed to the identifying causes and mechanisms of what was responsible for moving the economy from one stage to the next. Since the Azariadis and Drazen paper explores long-run changes in trends of EG and how it interacts with HD, their framework is clearly appropriate for our analysis, the more so since the threshold nature of the model explains why HD is not smoothly substitutable for other inputs as it is in more conventional growth models. Moreover, the empirical work in both this paper and RSR offer an identifiable channel, HD, by which an economy can move from a vicious to a virtuous cycle. ${ }^{10}$

Since these threshold models are most relevant to our empirical work, the question arises as to whether such thresholds have been detected empirically. Perron (1989) and Andrews (1993) provide the statistical tools to test for trend breaks in a given time series. In principle, such univariate tests could detect the threshold externality and link the change point to underlying causal factors such as HD. Alternatively, if we had a precise formulation of the country-specific dynamics linking HD and EG, we could estimate a series of country-specific VARs linking HD and EG. However, the time series dimension of the data used in this paper is far too limited to allow either of these two approaches to be feasible. ${ }^{11}$ The

\footnotetext{
${ }^{10}$ Galor and Weil (2000) develop a related model for the quantity and quality of children, and a dynamic interrelation between human capital and technological progress.

${ }^{11}$ However, time series data on individual countries or select groups of countries may be lengthy enough
} 
empirical approach we outline below does not formulate such precise dynamic relationships, but instead acknowledges that there is an underlying, country-specific, dynamic relationship that summarize by its key parameters.

The overall message from this brief survey of related literature is that, while human development has long been viewed both as an input and an outcome of the development process, the feedback and dual causality between HD and EG has not been fully or empirically taken into account. Once this dual causality is taken into account, it is obvious that any analysis of the determinants of EG or HD alone is incomplete. A feedback loop like that shown in Figure 1 implies that neither EG nor HD can be analyzed in isolation of the other if one wants to understand how an economy got to its current state and where it is going. The endogenous growth models allow for an explanation of cross-sectional differences in the growth experiences of countries, but Figure 1 requires models of the threshold externality type to understand changes over time within a given economy. This paper analyzes the latter, by allowing the strength of the feedback effects to vary by country.

\section{Growth Paths: Measuring the Strength of Links in Chain B}

In order to explore the relationship between HD and country growth over time, we require a measure for each country which captures the trend change in growth, which we shall term its 'growth trajectory'. The most common version of the time path of EG used in the empirical growth literature is the average growth in per capita income over an entire sample period (e.g. Barro and Sala-i-Martin (1992)), which has the virtue of averaging out short run fluctuations in growth, thus allowing the analyst to focus on explaining differences in country patterns of long run growth. ${ }^{12}$ However, for our purposes, this measure to allow such an approach in limited cases. Wallack (2003) is a recent example of this approach for Indian data from 1951 to 2001. Crafts (1995) and Crafts and Mills (1996) used this approach to study the growth path of British industrial production from 1700 to 1900. Jones (1995) used OECD data to argue that there has been no break in the trend of GDP per capita, yet innovative activity increased greatly over his sample period.

${ }^{12}$ This is not always the case. Islam (1995) uses fixed effects analysis in his study of convergence, thereby removing the purely cross-sectional variation in growth rates, and focusing on short run fluctuations in growth. Our strategy retains the virtue of Islam's approach by allowing for cross-country heterogeneity, but also keeps the focus on long run trends, thus by-passing one of the central criticisms of his approach. 
of growth is not appropriate. Since we think of the two Chains as embedded in the initial conditions and history of an economy, we want to exclude that information in deriving a measure of Chain B strength. ${ }^{13}$ To motivate this strategy, we return to the stylized neoclassical growth model, where (see Barro and Sala-i-Martin (1992)) the rate of growth in output per worker between period $t$ and $t-1$ for country $i$ is given by:

$$
g_{i t}=\left(1-e^{-\lambda}\right)\left[\log \left(\hat{y}_{i}^{*}\right)-\log \left(y_{i, t-1}\right)\right]+e^{-\lambda} x_{i}+\left(1+e^{-\lambda}\right) x_{i} t+\epsilon_{i t}
$$

where $x_{i}$ represents the once-and-for-all difference in technology across countries, $\hat{y}_{i}^{*}$ is the countryspecific steady-state level of output per effective worker, $y_{i, t-1}$ is the lagged level of output per worker, $\lambda$ represents the speed of convergence to the steady state, and $\epsilon_{i t}$ captures the transitory fluctuations in growth rates.

Before imposing any homogeneity assumptions, note that this model implies that growth rates across countries can be decomposed into a country-specific intercept, a country-specific trend, a convergence effect captured by the lagged level of output per worker, and the transitory component. Thus, the model implies the following factorization of growth rates:

$$
g_{i t}=\alpha_{i}+\beta_{i} t+\gamma_{i} \log \left(y_{i, t-1}\right)+\epsilon_{i t}
$$

where

$$
\alpha_{i}=\left(1-e^{-\lambda}\right)\left(\log \left(\hat{y}_{i}^{*}\right)\right)+e^{-\lambda} x_{i}
$$

\footnotetext{
${ }^{13}$ Furthermore, the effectiveness of the factors comprising the Chains potentially varies country-bycountry. Thus, we do not want an empirical strategy that looks at the effectiveness of individual links but instead at strategies that measure the strength of Chains A and B for each country as a whole. This approach may be a reduced form with regards to uncovering the structure of each Chain, but is required here as we do not want to impose stringent homogeneity conditions on the effectiveness of individual links across countries. The strategy we develop focuses on extracting what we refer to as the growth trajectory for each country as a measure of the strength of the Chain B links for each country. This growth trajectory helps us understand how growth rates are changing over time, therefore enabling us to address the RSR sequencing issue directly.
} 


$$
\beta_{i}=\left(1+e^{-\lambda}\right) x_{i}
$$

$$
\gamma_{i}=-\left(1-e^{-\lambda}\right)
$$

The cross-country growth literature (e.g. Barro and Sala-i-Martin (1992) Levine and Renelt (1992)) typically impose homogeneity assumptions on the coefficients $\alpha_{i}, \beta_{i}$, and $\gamma_{i}$, with the requirement that they are the same across countries. These three parameters are identified from the cross-sectional dimension of the data on long run growth rates, i.e. the time dimension of the data is averaged out. Our strategy is the opposite: we rely on the 40 year time span of the data to identify $\alpha_{i}, \gamma_{i}$, and especially $\beta_{i}$ for each country. $\beta i$ is therefore our measure of country i's growth trajectory. From equation (4) we can see that $\beta i$ gives us a clean representation of the empirical factors that drive growth (denoted as $\left.x_{i}\right) .{ }^{14}$ Note that, even though $x_{i}$ is also a component of the intercept $\alpha_{i}$ in the decomposition equation (2), this intercept is also affected by the steady state level of per capita income, which is likely a function of initial conditions and past history and thus does not characterize a clean representation of the RSR idea of the strength of Chain B. Since a least-squares fit of equation (2) will fit the time means of each country, the relationship the commonly used average growth rate $\bar{g}_{i}$ will obey is given by:

$$
\bar{g}_{i}=\hat{\alpha}_{i}+\hat{\beta}_{i} \frac{T+1}{2}+\hat{\gamma}_{i}{\overline{\log (y)_{i}}}_{i}
$$

Time-averaged growth rates are also a function of the country-specific intercept, and hence, of the country's steady-state per capita income levels. We therefore do not want to use these time-averaged growth rates. Instead, we opt to use the $\beta_{i}$ coefficients, i.e. the country-specific trend coefficients that we refer to as growth trajectories which are purged of dependence on steady-state differences.

\footnotetext{
${ }^{14}$ While $x_{i}$ is represented in the theoretical model as a scalar, our empirical strategy allows $x_{i}$, and thus $\beta_{i}$, to have a vector of determining factors.
} 
Note that our empirical approach is broader than this neoclassical theoretical foundation. The decomposition of growth rates in (2) is compatible with a large number of neoclassical and endogenous/threshold growth models, even though we relied on the Solow model to derive it. In the neoclassical formulation there are only the once-and-for-all factors summarized in $x_{i}$ that explain trend differences across countries. Endogenous growth models of the Uzawa-Lucas variety also explain per manent differences in growth trends but endogenize $x_{i}$, the source of permanent growth. Hence both exogenous and endogenous sources of growth will be captured by the trend coefficients in our estimates of equation (2), country-by-country. The question that then arises is how useful are the estimates obtained from equation (2) if the growth path is non-linear? In fact, we saw in the evidence presented above (Figure 3), that growth paths are often non-linear. In principle, we could use the 40 year time span of EG to fit a non-linear trend specific to each country. However, detecting trend breaks when using annual observations is not feasible in practice. If it were, we could potentially distinguish the threshold externality models that imply that differences in trend growth occur only across rather than within countries. Moreover, the linear trend will still be a good summary of the growth trajectory even if the underlying trend is non-linear, since our trajectory coefficient $\beta_{i}$ broadly indicates whether the path of EG is increasing, flat, or decreasing over the 40 year time span of our sample.

We obtain a measure of $\hat{\beta}_{i}$ by applying OLS to equation (2), for each country. ${ }^{15}$ This process generates

${ }^{15} \mathrm{An}$ issue arises in the estimation of the equation in terms of which per capita income series to use. Due to the presence of lagged income level as a regressor, whether we use a nominal or real series has a significant impact on the results, with the nominal series leading to much more variation in the $\hat{\beta}_{i}$ series. Since the regressions are country-specific, we do not need to convert per capita incomes to PPP or world prices. Problems with using PPP estimates, including the pricing of non-traded goods and services, and biases due to relative price shifts have been discussed by Bhagwati and Hansen (1973), Nuxoll (1994) and Srinivasan (1995). Our procedure for estimating the $\hat{\beta}_{i}$ coefficients therefore involves using current per capita series on growth and income. But we need to allow for inflation since the data is all in current prices. We pre-filter all the per capita income series of region, time, and region-by-time effects (remember that we use the lagged level of per capita incomes in estimating the $\hat{\beta}_{i}$ coefficients). We also pre-filter the growth rates of time effects as world growth rates tend to have a certain trend over time and we would like to account for that. We then use the filtered growth rates and lagged per capita levels in the country-by-country estimation of equation (3). Use of the raw series preserves more of the variation and gives stronger results than those presented here but we want to avoid results driven by potentially nominal effects. 
the country-specific growth trajectories, $\hat{\beta}_{i}$, which essentially are the average rate of change of the growth rate and that we take to be a measure of the strength of Chain B. Keep in mind that a country can have a positive growth trajectory, with $\hat{\beta}_{i}>0$, yet have negative average growth, $\bar{g}_{i}<0$. All but 10 countries have growth trajectories within the range of -0.2 to $0.2-\hat{\beta}_{i} \approx 0$, i.e. actual growth rates that are neither increasing nor decreasing. Average growth rates over the period, by contrast, vary much more widely across countries. Barro (1997) and Quah (1996) note that the time-series movements in per capita output are a trivial fraction of the cross-country variation in levels of output per capita. Having derived our measure of the growth trajectory, the next step is to ask what its empirical determinants are, particularly its relationship to levels and changes in HD.

The evidence on sequencing presented in Figure 3 and Table 1 above led us to hypothesize that HD levels and/or improvements affect countries' growth trajectories. We therefore investigate the relationship between HD levels, HD changes, and $\hat{\beta}_{i}$. This relationship is an indication of the strength of Chain $\mathrm{B}$. We also explore the role of more conventional explanatory factors of EG (as in Levine and Renelt (1992)), such as investment and export ratios, in determining the growth trajectory. However, since such factors are generally associated with actual growth rates, we would anticipate that only their changes would explain the growth trajectory, $\hat{\beta}_{i}$. We specify our empirical model as follows:

$$
\hat{\beta}_{i}=\eta+H D_{i}^{\prime} \tau+z_{i}^{\prime} \theta+\zeta_{i}
$$

where $i=1, \ldots, 81$, the number of countries for which we have data; and $z_{i}^{\prime}$ represents the other factors influencing $\hat{\beta}_{i}$ noted above, as well as three regional dummies. The presence of the error term $\zeta_{i}$ highlights another advantage of our two-step estimation procedure in that it allows for heterogeneity in the Chain B measure for reasons that are not purely due to HD. Our focus is on the estimated value(s) of the coefficient vector $\tau$, as we hypothesize that higher levels of HD lead to higher (more positive) growth trajectories, and vice versa. While specific theoretical models dictate whether the variables should be entered in the form of levels or changes, we treat this as an empirical issue and consider a variety of specifications. ${ }^{16}$ Since HD is a product of EG, via Chain A, in order to reduce the problem of reverse

${ }^{16}$ The extended neoclassical framework of Mankiw, Romer, and Weil (1992) implies that stocks or levels of HD drive growth. However, Benhabib and Spiegel (1994) find that HD levels explain little of EG itself, but that the human capital stock interacted with the diffusion of innovations (as in the analysis of Nelson 
causality we use data from early in the sample period. The results are presented in Table 4, using infant mortality rates, life expectancy and school enrollment rates as measures of HD. Columns (1) through (6) include levels of early HD as the explanatory variable while Columns (7) through (12) show the specifications with changes in early HD.

\section{INSERT TABLE 4}

The results of the basic specification, using the 'early' (1960 to 1980 average) Infant Mortality Rate (IMR) as a measure of HD, are shown in Column 1 of Table 4. Larger values of IMR indicate a lower level of HD, so that we would expect to see an estimated $\tau$ that is negative. Note that since the dependent variable here is the fitted time trend from the decomposition in equation (2), the actual value of the coefficient on IMR is difficult to interpret. We focus on comparing the relative size of the coefficients on the regressors, as well as observing their statistical significance. From Column 1, we can see that a higher IMR implies a country is less likely to have a positive growth trajectory. In Columns 2 and 3 we repeat the exercise, using Life Expectancy (LE) and the Gross Secondary Enrollment Rate as the second and third measures of HD, respectively. ${ }^{17}$ We look at each HD variable separately as they are highly correlated and measuring their separate influence within one regression is not possible. The schooling effect is less precise than the IMR and LE effects, but this is partially due to the lower variance in secondary enrollment rates (the standard deviation of the enrollment rate is about half that of IMR across countries). On the whole, the initial levels of various aspects of HD are strongly related to subsequent positive growth trajectories, $\hat{\beta}_{i}$.

Columns (4) through (6) repeat the specifications for HD, but now using the changes (as opposed to the levels) in the investment and export ratios as additional regressors. We can see from Columns (1) to (3) that investment and exports are still operative mechanisms influencing growth, but only increasing investment and export rates lead to increasing growth trajectories, and not the levels themselves, as is the case with HD. Columns (7) through (12) repeat the exercise, but now focusing on the role of HD and Phelps (1966)) is significant. The endogenous growth models along the lines of Uzawa-Lucas generally imply that HD changes are the reproducible factor driving sustained growth. Finally, the threshold model of Azariadis and Drazen (1990) implies that HD levels govern the threshold at which an economy transits from one growth trend to another.

${ }^{17}$ Average primary enrollment rates vary much less across countries and tend to 'top out' at values over 100 percent. Their estimated effects are less precise and reliable so we do not report them. 
changes. As before, we use the change in HD over the first half of the sample, 1960 to 1980 . These latter results are slightly less precise than the corresponding estimates in Columns (1) through (6) that look at HD levels. But, the results on levels and changes in export and investment ratios are similar across the Table.

Graphical versions of the HD relations in Table 4 are displayed in Figures 4, 5 and 6 for IMR, LE and Secondary Enrollment, respectively, by region. These figures also give us a picture of what the growth trajectories look like across our sample of countries. It is interesting to note some of the patterns within and between regions. First, the Middle East has the lowest average $\hat{\beta}_{i}$, as the growth rates of these countries are partly driven by wealth in natural resources, the impact of the extended "Dutch Disease", plus declining marginal productivity of resources. And, in contrast to their low average growth rates, the African countries score close to the world average on their $\hat{\beta}_{i}$ 's. Across all regions, Mauritius and Korea score the highest, though Hong Kong and Singapore are not far behind. The Democratic Republic of the Congo, Ethiopia, and Cambodia are at the low end of our growth trajectory measure, with Iran not far behind. From a power perspective, it is important to note that, apart from these 8 countries, the remaining countries' growth trajectories lie between -0.2 and 0.2 , showing very little variation.

Within regions, the Figures illustrate that the relationship between early HD levels and estimated growth trajectories is clearly the strongest in Asia. The relationship is not strong within Latin America or the Middle East (note the low variation in estimated growth trajectories for the former). Of course, changing oil prices in the Middle East and the debt crisis in Latin America greatly influenced their growth trajectories. In this case, the crisis in Latin America and its effects on our empirical framework shows the difficulties of employing this approach with a time window as narrow as 40 years.

\section{INSERT FIGURE 4}

\section{INSERT FIGURE 5}

\section{INSERT FIGURE 6}

In summary, in terms of the strength of Chain $\mathrm{B}$, there is clear evidence of a positive relationship between early HD levels - more so than changes - and countries' growth trajectories, implying that promoting HD early on is an important element in generating an acceleration in growth, as indicated by the evidence on sequencing presented earlier. By contrast, only changes in the variables normally thought to determine EG - the investment and export ratios - appear to be relevant. In the context of a threshold 
externality model, if we interpret the threshold as a country-specific level of HD, the results in Table 4 lend such a model strong support. These results indeed also show weak support for a model without such 'pre-conditions', as in an Uzawa-Lucas type model where HD is simply an input to production. However, they provide stronger evidence for the view that HD is non-substitutable, but must reach some threshold level before the transition is made from a low level to a high level equilibrium. Determining a specific threshold level of HD that is a necessary prerequisite for achieving accelerating growth would, however, go beyond the scope of this paper.

\section{From GDP to Human Development : Measuring the Strength of the Links in Chain A}

In the case of Chain A, data availability, over time, is more limited than in the case of Chain B, permitting less investigation of country-specific heterogeneity. Moreover, theoretical and conceptual models to account for what generates HD improvements are not as developed as those explaining EG. In constructing an overall measure of the strength of Chain A, we therefore are forced to rely on the cross-sectional relationship between EG and HD improvements to generate a country-specific measure. We use the lags inherent in enhancing HD levels from higher EG to reduce the problem of reverse causality.

In order to construct a measure of the overall strength of Chain A for each country, we use countryspecific fitted residuals from a regression of 'late' (1980-2000) HD improvements on 'early' EG (1960-1980). The idea is that, given initial growth, countries that have better HD at the end of the sample period (i.e. higher fitted residuals) are inferred to have been more effective in translating EG into HD, presumably because they have invested more of the profits of initial growth into developing their HD infrastructure, and hence have stronger links in Chain A. To formalize our measurement strategy, let the early and late halves of our sample be represented by the 0 and 1 subscripts, respectively, so that, in principle, we can use the following equation to estimate the country-specific strengths of Chain A:

$$
\Delta H D_{i 1}=\kappa+\psi_{i} g_{i 0}+\xi_{i}
$$


where the country-specific conversion of dollars of early growth into HD is given by the country-specific slope $\psi_{i}$. Unfortunately, this regression has only 80 observations, but 81 parameters, to estimate if the slope parameters are allowed to be heterogeneous. If we wished to pursue this strategy, we could try to push the time series dimension to its limits and extract 2 or 3 time periods per country, but in so doing we would have to make much more precise assumptions on the lag structure in the above model. While, in principle, this approach is roughly consistent with our Chain B approach discussed above, in practice the smaller number of time series points makes this far too imprecise to be a viable strategy.

Instead, we turn to the cross-sectional relationship between $\Delta H D_{i 1}$ and $g_{i 0}$ and ask: for a given early growth $g_{i 0}$, what is the later improvement in HD? The answer to this question is simply the fitted residual to the homogeneous slope coefficient regression:

$$
\Delta H D_{i 1}=\kappa+\psi g_{i 0}+v_{i}
$$

Call this fitted residual $\hat{v}_{i}$. Note that by the mechanics of OLS, this measure is independent of $g_{i 0}$, and note further that interpreting this measure of the strength of Chain A when compared to the slope measure above implies that:

$$
v_{i}=\xi_{i}+\left(\psi_{i}-\psi\right) g_{i 0}
$$

If the regression error, $\xi_{i}$, is small, i.e. if a necessary condition for HD improvement is growth in income, EG, which represents the view that EG is 'instrumental' for HD, then this cross-section-based method using the fitted residuals will largely reflect the efficiency of converting early EG into later HD improvements. Thus $\hat{v}_{i}$ will serve as a suitable measure of the strength of the links in Chain A, given a particular measure of HD.

To construct a measure of the relative overall strength of Chain A for each country, therefore, we use the country-specific residuals from a regression of HD improvements, 1980 to 2000, on EG, from 1960 to 1980. This measure of Chain A strength is thus independent of early EG by construction, and yet we find that it has a strong positive correlation with growth at the end of the sample period. Here again, the lag time in producing HD reduces the possibility of simultaneity driving this clear, positive relationship. 
The multidimensional nature of HD means that we arrive at different fitted residuals (i.e. strengths of Chain A) according to the measure we select. To capture two of the dimensions of HD, health and education, we use the IMR shortfall reduction and the secondary school enrollment shortfall reduction, both for the latter half of the sample (1980 to 1995). ${ }^{18}$ For both these series we fit a regression relating EG, 1960-1980 to HD, 1980-1995. The regression line represents the systematic relation of a rupee of early EG to HD improvements 20 years later. The regression lines, and the associated data points, are shown in Figures 7 and 8. There, a country's vertical deviation from the regression line represents its relative Chain A strength. The Figures show that, across countries, higher early EG generally leads to better HD improvements at the end of the sample period. But the connection is not automatic, as countries such as Oman and Gabon show quite high growth, yet only average HD improvements. Similarly, countries such as Chile and Sri Lanka have only average early EG, yet have substantially better-than-average HD improvements at the end of the period. Some explanation for these deviations will be considered below. In Figure 7 (where IMSR is the HD measure), Singapore stands out as having the largest reduction in IMR for a given amount of early growth, while Chile, Malaysia, and Trinidad are also low early growth countries that nonetheless had very large reductions in IMSR. Because our Chain A measure conditions on initial growth, these countries actually score better on the Chain A strength than do Korea or Saudi Arabia, which had about the same IMSR, but which had much higher early growth as well.

Figure 8 presents the same relationship, now using secondary enrollment shortfall reductions in place of IMSR. In this case Uruguay scores best, while Hong Kong, the country with almost the strongest Chain A links when using IMR as the measure of HD, is seen to be quite close to the fitted regression line, and thus only about average. Egypt and Chile, while showing quite different early growth rates, exhibit roughly the same strength of Chain A. Sri Lanka is one of the few countries to do quite well on both measures of HD, while the Dominican Republic, Gabon, Syria and Ecuador perform relatively poorly when using secondary enrollment.

\section{INSERT FIGURE 7}

\section{INSERT FIGURE 8}

Our measures based on these HD indices individually have compensating strengths and weaknesses.

${ }^{18}$ Gross primary school enrollments are near 100 percent for most of our countries by the end of the sample period. Tertiary enrollments, by contrast, are mostly quite low, and are generally less reliable. 
IMSR has the virtue that the lag time from initial growth until the improvements in HD are realized is likely quite short as compared to other aspects of HD. The downside of using IMSR is that reducing IMR may be less of a target once the level of IMR gets sufficiently small. Enrollment data have the virtue of addressing the human capital element of HD, which is a key factor both as an input and as an outcome. However, enrollments have an appreciable lag time, i.e. in developing the infrastructure to support higher enrollments it is necessary to train teachers, build schools, etc. Enrollments also have the drawback of not accounting for the quality of schooling. Therefore, we also construct an index based on both of these HD measures. We use the simple average of the two sets of residuals to construct an overall index of the relative strength of Chain A. In terms of this index, then, the countries with strong Chain A links are Uruguay, Chile, Sri Lanka, Algeria, and Korea, and those with the weakest Chain A linkages are Gabon, Papua New Guinea, and Botswana.

The country differences in the relative strength of Chain A are due to a variety of structural and policy factors which determine the efficiency with which GDP resources are converted into HD outcomes. As discussed earlier, these are likely to include the poverty rate and the distribution of income, social expenditure ratios and the relative position of women. ${ }^{19}$ To investigate some of the specific sources of the Chain A strengths, we analyze them (as we did with the Chain B measures in Table 4) with a set of variables suggested by Figure 1. The results are presented in Table 5, which uses the combined index for the strength of Chain A. Due to the collinearity between public expenditure per capita on education and health we report regression specifications on them separately. Both per capita public expenditure on education and health are significantly related to the relative strength of Chain A, while the extent of inequality is shown to be strongly inversely related. The relationship to government expenditure priority ratios (Columns 3 and 4) displays essentially no effect. Our ability to explain Chain A strength is rather modest, apart from the Gini coefficient which shows up as an important explanatory factor. Note that regional dummies confirm that the strength of Chain A is lower in Africa where, again, AIDS is likely to be relevant than elsewhere. A more in-depth analysis is needed to uncover the sources from which Chain A derives its strength; owing to the variety of policy mixes that can produce strong chains, this is an exercise beyond the scope of this paper. The graphical versions of these Tables are shown in Figures 9

\footnotetext{
${ }^{19}$ Ranis and Stewart (2000) found that different possible combinations of such factors can produce overall strong Chain A links. Such policy mixes could well be country specific as well as dependent on the stage of development, which makes it a complex problem.
} 
and 10. Figure 9 shows the relationship between Chain A strength and per person public expenditure on education in 1970 and Figure 10 the analogous relationship for per person public expenditure on health.

\section{INSERT FIGURE 9}

INSERT FIGURE 10

In summary, we find a strong relationship between early EG and later HD on average, indicating the general strength of Chain A. Deviations from the average relationship, which measure country-specific strengths of Chain A, seem to be strongly influenced by the distribution of income, less so by social expenditure ratios.

\section{The Virtuous, The Vicious, and the Lopsided: Implications for Sequencing}

Our goal so far has been to measure the strengths of the overall chains linking HD to EG (Chain B) and EG to HD (Chain A) separately. We are now in a position to consider how the two chains reinforce each other in generating vicious and virtuous outcomes, or which lead to short-run lopsided outcomes when one chain is comparatively stronger than the other. It is important to bear in mind that the chain measures capture the strengths over the duration of the sample, and by design do not incorporate information on the levels of HD or EG. Thus our portrayal of the joint Chain A and Chain B strengths will predict only short-run outcomes, and long-run prediction would require re-introducing the information on the levels of HD and EG and suitably combining that information with our Chain A and Chain B measures.

The main conclusion from our earlier examination of the decade by decade experiences concerns sequencing: HD upgrading early in the period is essential for greater subsequent growth, as illustrated in Figure 2. Improved growth in turn feeds back into improved HD. Strong long-run growth without accompanying strong HD improvements do not appear to yield a stable equilibrium over this time period. Furthermore, our sequencing analysis indicates that HD is not a substitutable factor, like capital and labor in a neoclassical framework, but behaves more like a necessary precondition for sustained growth, as in the Azariadis-Drazen threshold externality framework. It delivers the policy implication that structuring 
policy to produce strong HD can tip an economy from a low EG to a high EG state and thus secure the further health and well-being of its population.

\section{INSERT FIGURE 11}

Further evidence on sequencing is given in Figure 11, which shows the relationship between the combined strength of the Chain A index and late EG (from 1980 to 2001). From Figure 11, we can see that the overall strength of Chain A correlates strongly with late EG, indicating a subsequent round of positive interaction. This supports the sequencing hypothesis implied by Figure 2. We should emphasize that the Chain A index is independent of initial growth by construction, and the strong relation to subsequent growth is therefore by no means automatic. Inspection of the data points and their deviations from the regression line illustrate some failures to perfectly predict which countries will enjoy greater subsequent growth - e.g. China seems to have performed substantially better than our index would have suggested, and Nicaragua under-performed relative to what the index implies.

Having constructed the overall Chain measures to capture the policy strengths on both sides of the feedback loop in Figure 1, the question now is how to put these measures together to be able to predict where countries should be in the future, vis a vis their EG and HD outcomes. We can incorporate the information in the two measures we derived for Chains A and B by simply plotting these two measures against each other. This lets us inspect which countries have strong, mutually reinforcing Chain A and Chain B links and therefore which countries we would expect to have sustained growth in the longer run. Similarly, we can see which countries have Chain A and B links that would lead them to poor HD-EG outcomes unless they start upgrading their HD.

\section{INSERT FIGURE 12}

Figure 12 therefore shows the strengths of the two Chains over the sample period. The aim of this figure is purely to put together the two measures we developed earlier to illustrate the expected performance of countries, with respect to their Chain A and B strengths. For example, countries like Korea, Hong Kong, Uruguay, and Chile have strong positive links in both Chains A and B, and we would therefore expect them to reach the high (HD, EG) plateau and be able maintain their growth performance in the future. On the other side, we can see countries like Pakistan, Nigeria, Chad, and Burundi that tend to score low on both our measures and whom we therefore expect to perform poorly over the long-run unless there is a change in their HD priorities. Not surprisingly, many of the countries in East Asia and 
Latin America have strong linkages in both chains. Indeed, outside of these two regions only Tunisia and Egypt in the Middle East, and Sri Lanka in South Asia are countries that we estimate to have strong dual linkages that would tend to push them to the virtuous (HD-EG) plateau.

Finally, we comment on the over-representation of countries in the EG lopsided quadrant. As we discussed above, our chain measures by construction discarded information on levels. However, the threshold model of Azariadis and Drazen and the empirical analysis of RSR is predicated on HD levels. As our analysis is constructed to abstract from initial conditions and thus the levels of HD, Figure 12 should not be expected to mimic the realized outcomes given in Figure 2. Were we to combine the rankings on the HD levels with the predicted outcomes in Figure 12, this would push the few African countries in the EG-lopsided into the vicious quadrant, consistent with their actual experience. Alternatively we view the 'predictions' of Figure 12 as alludng to the future paths of the countries in the sample, and the comparative strengths and weaknesses of their Chains A and B. As a strong Chain B without an accompanying strong Chain A implies that high EG is not sustainable, we would expect the countries in the lower right-hand quadrant to experience high EG for a temporary period at best. Figure 12 thus identifies a number of countries with EG-centric policy mixes that would be well served, in terms of long run growth and human development, by giving priority to enhancing their HD infrastructures.

\section{Conclusion}

The aim of this paper has been to understand the two-way linkages between HD and EG, accounting for the fact that HD is likely to be not just an end product of growth, but an input as well and a key ingredient in the development process. Education, health, and other aspects of HD involve fixed costs that can create non-convexities in the social returns to various levels of HD, and thus result in low and high level equilibria. This paper is concerned with how to measure the strength of the overall chains linking EG to HD, following earlier evidence by Ranis, Stewart, and Ramirez (2000).

In Section 2 we updated the relationships identified by RSR, relating HD and EG cross-country over time, using average growth as our measure of EG and absolute levels and changes in several definitions of HD. In Sections 3 and 4, we presented more sophisticated measures of EG and HD and used these to explore their interrelationship. In this case our aim was to explore individual country EG and HD 
performance. In the case of EG, we developed the notion of country growth trajectories which basically are defined as the trend change in growth in each country. In the case of HD, the relative strength of Chain A for each country was defined by the deviations from the overall cross-country relationship between early average economic growth and later improvements in HD.

While there are evident positive relationships between HD and EG, they are not automatic in either direction. This paper has explored some of the factors explaining why some countries have particularly strong Chains. In the case of Chain A, our investigations suggest that social expenditure ratios and income distribution are important contributory factors. In the case of Chain B, it is the levels and changes in HD and changes in investment ratios that are important contributing factors to the growth trajectory. Of course, in both cases this omits other factors that are often emphasized, such as the quality of the social services, and the prevalence of social capital in the case of A, and geography, institutions and the policy environment in the case of $\mathrm{B} .{ }^{20}$ We also showed how HD improvements must precede growth-oriented policies if growth is to be sustained. These sequencing and level effects of HD contradict the usual neoclassical view whereby all inputs to production are substitutable. The sequencing finding also contradicts the conventional view that HD is purely a result of, as opposed to being a critical input into long run expansions in EG.

The findings of long-run differences in growth paths, not only across countries but also within a given country over time, restrict the class of theoretical models that can explain such phenomena. Endogenous growth models of the Uzawa (1965) and Lucas (1988) type only explain long run differences in growth across countries when they have differing propensities to upgrade HD. In contrast, threshold externality models along the lines of Azariadis and Drazen (1990) were constructed precisely to explain the type of phenomenon found in this paper, i.e. why transitions from a vicious (low EG low HD) state to a virtuous (mutually re-enforcing high EG high HD) state over time are blocked unless HD is sufficiently strong before EG centered policies are attempted.

${ }^{20}$ See North (1990), Sachs (2001) and Acemoglu, Johnson and Robinson (2002). 


\section{References}

[1] Acemoglu, Daron, S. Johnson, and James Robinson, (2002), "Reversal of Fortune: Geography in the Institutions in the Making of the Modern World Income Distribution", Quarterly Journal of Economics, CXVII, 1231-94.

[2] Aghion, Philippe and Peter Howitt, (1998), Endogenous Growth Theory, MIT Press, 1998.

[3] Andrews, Donald, W.K., (1993), "Tests for Parameter Instability and Structural Change with Unknown Change Point", Econometrica, 61(4), 821-856.

[4] Aturupane, Harsha, Paul Glewwe and Paul Isenman, (1994), "Poverty, Human Development and Growth: An Emerging Consensus?", American Economic Review, Papers and Proceedings, 84(2), 244-249.

[5] Azariadis, Costas, and Alan Drazen, (1990), "Threshold Externalities in Economic Development", The Quarterly Journal of Economics, 105(2), 501-526.

[6] Barro, Robert, (1997), Determinants of Economic Growth: A Cross-Country Empirical Study, Lionel Robbins Lectures, MIT Press.

[7] Barro, Robert and Xavier Sala-i-Martin, (1995), Economic Growth, Advanced Ser ies in Economics, McGraw-Hill.

[8] Barro, Robert and Xavier Sala-i-Martin, (1992), "Convergence", Journal of Political Economy, $100(2), 223-251$.

[9] Benhabib, Jess, and Mark M. Spiegel, (1994), "The Role of Human Capital in Economic Development: Evidence from Cross-Country Data", Journal of Monetary Economics, 34, 143-173.

[10] Bowman, Mary Jean and C. Arnold Anderson, (1963), "Concerning the Role of Education in Development", in Clifford Geertz ed. Old Societies and New States, New York: Free Press, 247-279.

[11] Crafts, Nicholas, (1995), "Exogenous or Endogenous Growth? The Industrial Revolution Reconsidered," The Journal of Economic History 55(4), 745-772. 
[12] Durlauf, Steven and Danny Quah (1999), "The New Empirics of Economic Growth", in Taylor, John and Michael Woodford, eds., Handbook of Macroeconomics, Volume 1A, Elsevier Science, NorthHolland, 235-308.

[13] Durlauf, Stephen and Johnson, (1995), "Multiple Regimes and Cross-Country Growth Behaviior", Journal of Applie Econometrics, 10, 365- 384.

[14] Hirshman, Albert, O., (1958), The Strategy of Economic Development, New Haven, Yale University Press.

[15] Kakwani, Nanak, (1997), "Growth Rates of Per-Capita Income and Aggregate Welfare: An International Comparison", The Review of Economics and Statistics, 79(2), 201-211.

[16] Kuznets, Simon, (1963), "Notes on The Take-off," in W. W. Rostow ed. The Economics of Take-off Into Sustain Growth, London: St. Martin's Press.

[17] Levine, Ross and David Renelt, (1992), "A Sensitivity Analysis of Cross-Country Growth Regressions", American Economic Review, 82(4), 942- 963.

[18] Lewis, Arthur, (1955), The Theory of Economic Growth, London, George Allen and Unwin.

[19] Lucas, Robert, (2002), Lectures on Economic Growth, Harvard University Press, 2002.

[20] Lucas, Robert, (1988), "On the Mechanics of Economic Development", Journal of Monetary Economics, 22(1), 3-42.

[21] Mankiw, Gregory N., David Romer, and David Weil, (1992), "A Contribution to the Empirics of Economic Growth", Quarterly Journal of Economics, 407-437.

[22] Mills, Terence and Nicholas Crafts, (1996), "Trend Growth in British Industrial Output, 1700-1913: A Reappraisal," Explorations in Economic History 33, 277-295.

[23] Murphy, Kevin, M., Andrei Schlefer and Robert W. Vishny, (1989), "Industrialization and the Big Push", Journal of Political Economy, 97(5), 1003-1026.

[24] North, Douglas, (1990), Institutions, Institutional Change and Economic Performance, New York, Cambridge University Press. 
[25] Nuxoll, Daniel, (1994), "Differences in Relative Prices and International Differences in Growth Rates", American Economic Review, 84(5), 1423-1436.

[26] Nurkse, R., (1952), Problems of Capital Formation in Underdeveloped Countries, Basil Blackwell.

[27] Perron, (1989), "The Great Crash, The Oil Price Shock and the Unit Root Hypothesis", Econometrica, 57(6), 1361-1401.

[28] Pesaran, Hashem and Ron Smith, (1995), "Estimating Long-run Relationships From Dynamic Heterogeneous Panels", Journal of Econometrics, 68(1), 79-113.

[29] Psacharopolous, George, (1994), "Returns to Investment in Education: A Global Update", World Development, 22.

[30] Quah, Danny, (1996), "Empirics for Economic Growth and Convergence", European-EconomicReview, 40(6), 1353-75.

[31] Ranis, Gustav, (1984), "Typology in Development Theory: Retrospective and Prospects" in eds. Moshe Syrquin, Lance Taylor, and Larry Westphal, Economic Structure and Performance, Academic Press, London.

[32] Ranis, Gustav, Frances Stewart and Alejandro Ramirez, (2000), "Economic Growth and Human Development", World Development, 28(2), 197- 219.

[33] Ranis, Gustav and Frances Stewart, (2000), "Strategies for Success in Human Development", Journal of Human Development, 1(1), 49-69.

[34] Romer, Paul, (1986), "Increasing Returns and Long-run Growth", Journal of Political Economy, $94(5), 1002-37$.

[35] Rosenstein-Rodan, (1943), "The Problem of Industrialization of Eastern and South-Eastern Europe", Economic Journal, 53, 202-211.

[36] Rostow, W. W., (1960), The Stages of Economic Growth, Cambridge, UK, Cambridge University Press. 
[37] Sachs, Jeffrey, (2001), “Tropical Underdevelopment”, NBER Working Paper 8119, Cambridge, Mass., NBER.

[38] Schultz, Theodore W., (1963), The Economic Value of Education, New York, Columbia University Press.

[39] Sen, Amartya, (1992), Inequality Reexamined, Cambridge: Harvard University Press for the Russell Sage Foundation.

[40] Solow, Robert (1956), “A Contribution to the Theory of Economic Growth", The Quarterly Journal of Economics, 70(1), 65-94.

[41] Solow, Robert, (2000), Growth theory: An Exposition, Second Edition, Oxford University Press, 2000.

[42] Srinivasan, T.N., (1994), "Database for Development Analysis: An Overview", Journal of Development Economics, 44(1), 3-28.

[43] Srinivasan, T.N., (1994), "Human Development: A New Paradigm or Reinvention of the Wheel?", American Economic Review, Papers and Proceedings , 84(2), 238-243.

[44] Srinivasan, T.N., (1995), "Long-Run Growth Theory and Empirics: Anything New?", in Ito and Krueger, eds. Growth Theories in Light of the East Asian Experience.

[45] Streeten, Paul (1994), "Human Development: Means and Ends", American Economic Review, Papers and Proceedings , 84(2), 232-237.

[46] Sugden, Robert (1993), "Welfare, Resources, and Capabilities: A Review of Inequality Reexamined by Amartya Sen", Journal of Economic Literature, 31, 1947-1962.

[47] United Nations Development Program, Human Development Report, Various Issues.

[48] Wallack, Jessica Seddon, (2003), "Structural Breaks in Indian Macroeconomic Data”, Economic and Political Weekly, 4312-4315.

[49] Uzawa, Hirofumi, (1965), “Optimum Technical Change in an Aggregative Model of Economic Growth", International Economic Review, 6(1), 18-31. 
[50] World Bank, World Development Indicators, Various Issues and Online Database. 


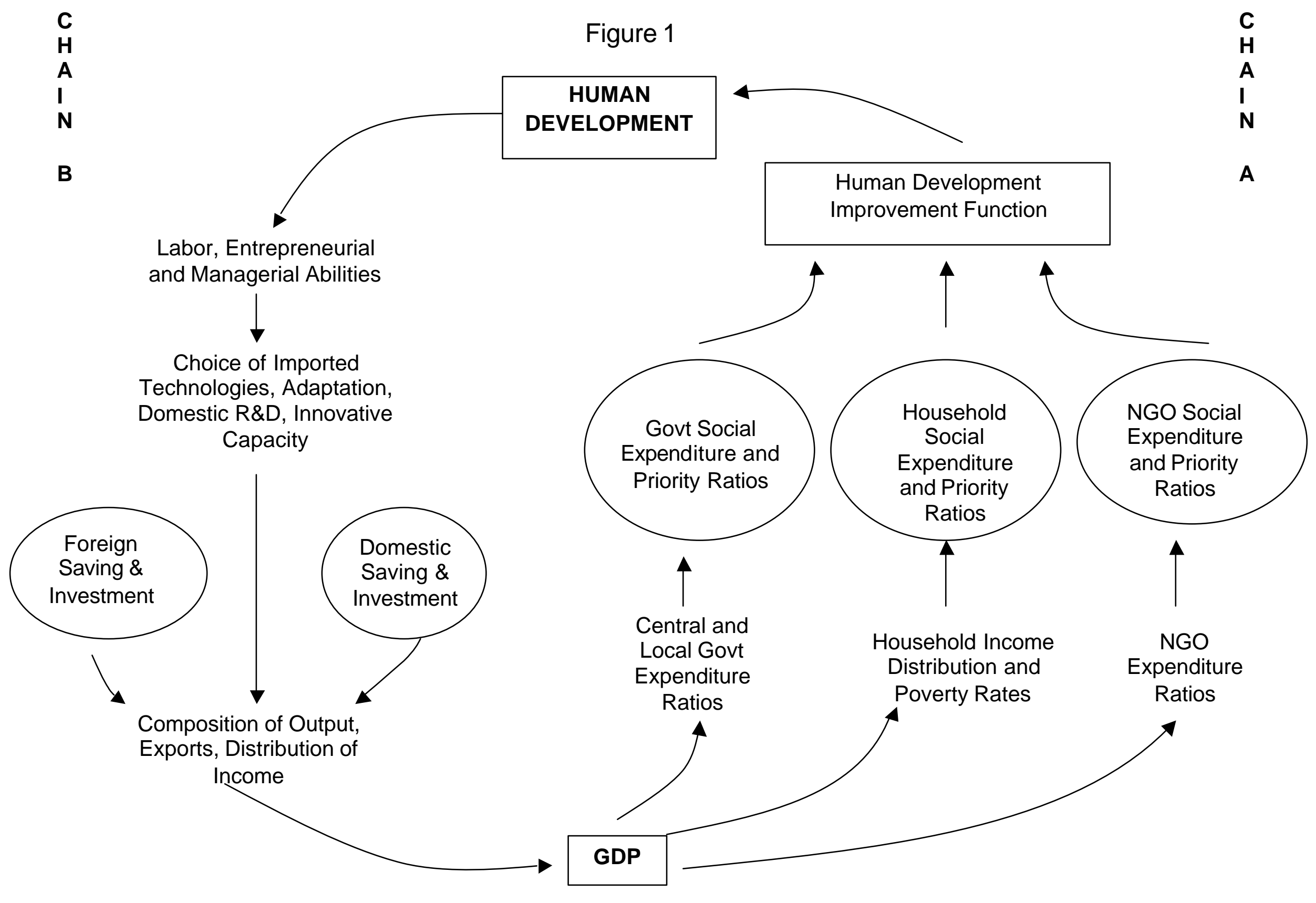


Figure 2

HD and EG Performance, 1960-2001

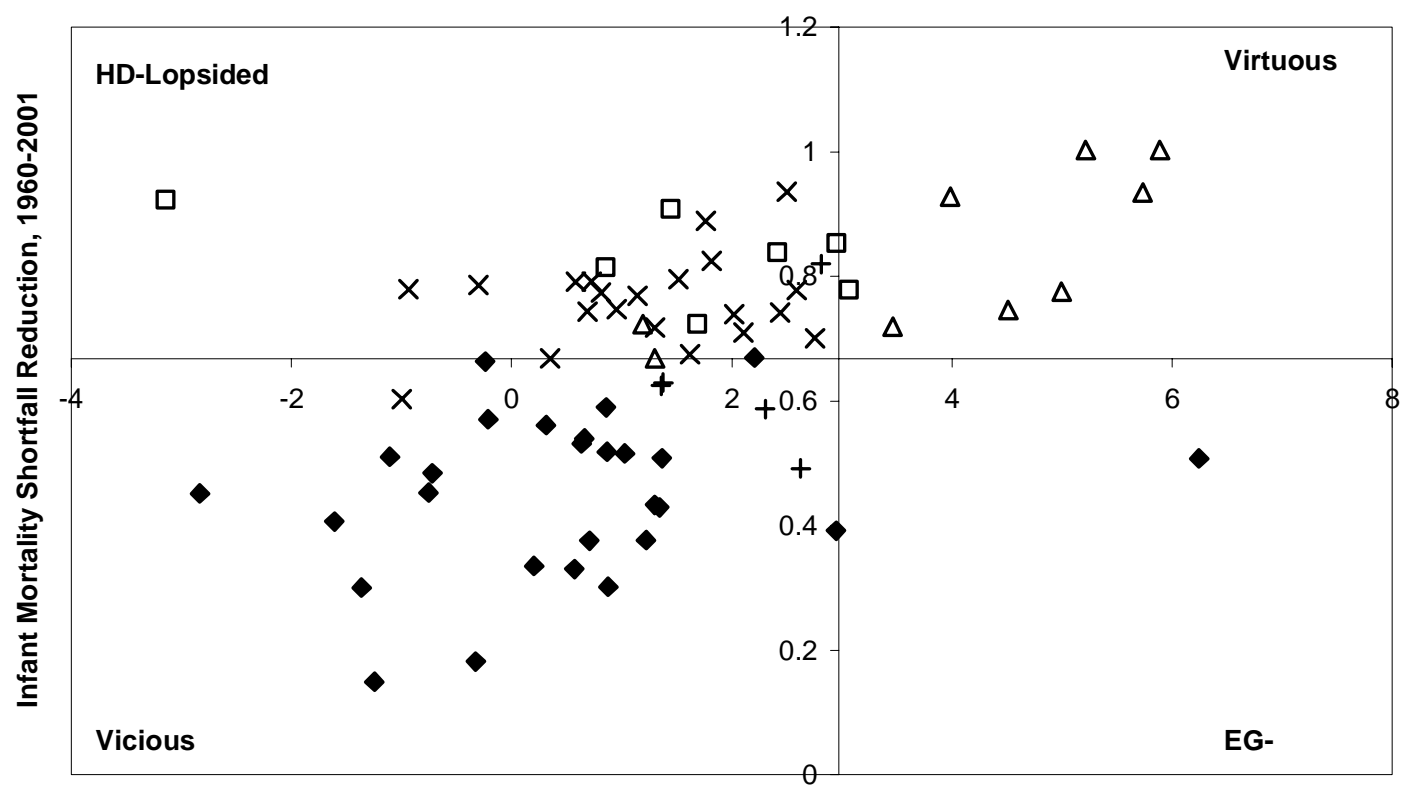

- Africa

$\square$ Middle East

$\Delta$ East Asia

$\times$ Latin America

+ South Asia

Average Annual GDP Per Capita Growth, 1960-2001

Figure 3

Country HD-EG Quadrant Changes over Four Decades, 1960-2001

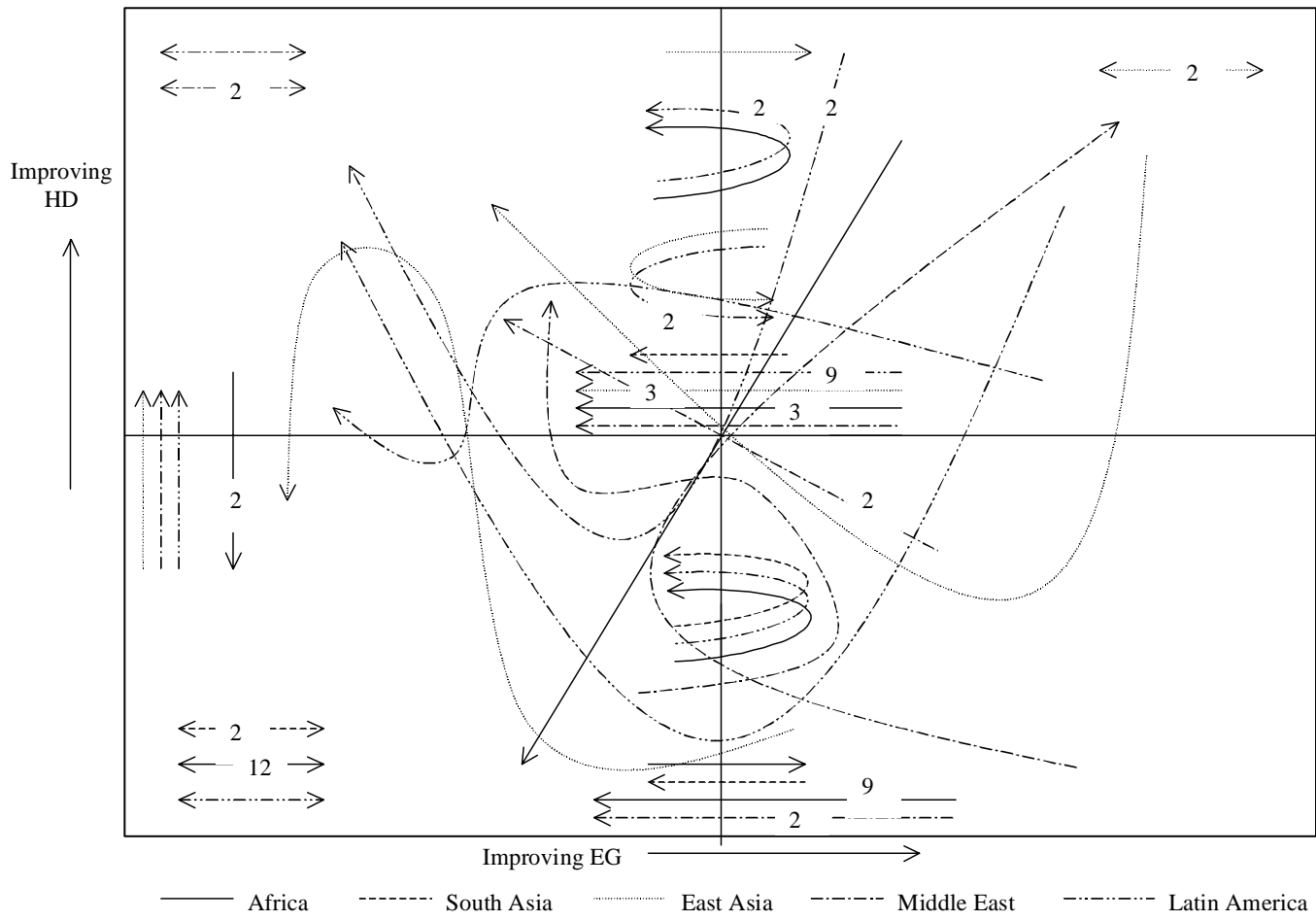

Note: The numbers on this figure refer to the number of countries (in a given region) making the transition shown. 


\section{Explaining Growth Trajectories with Early IMR}

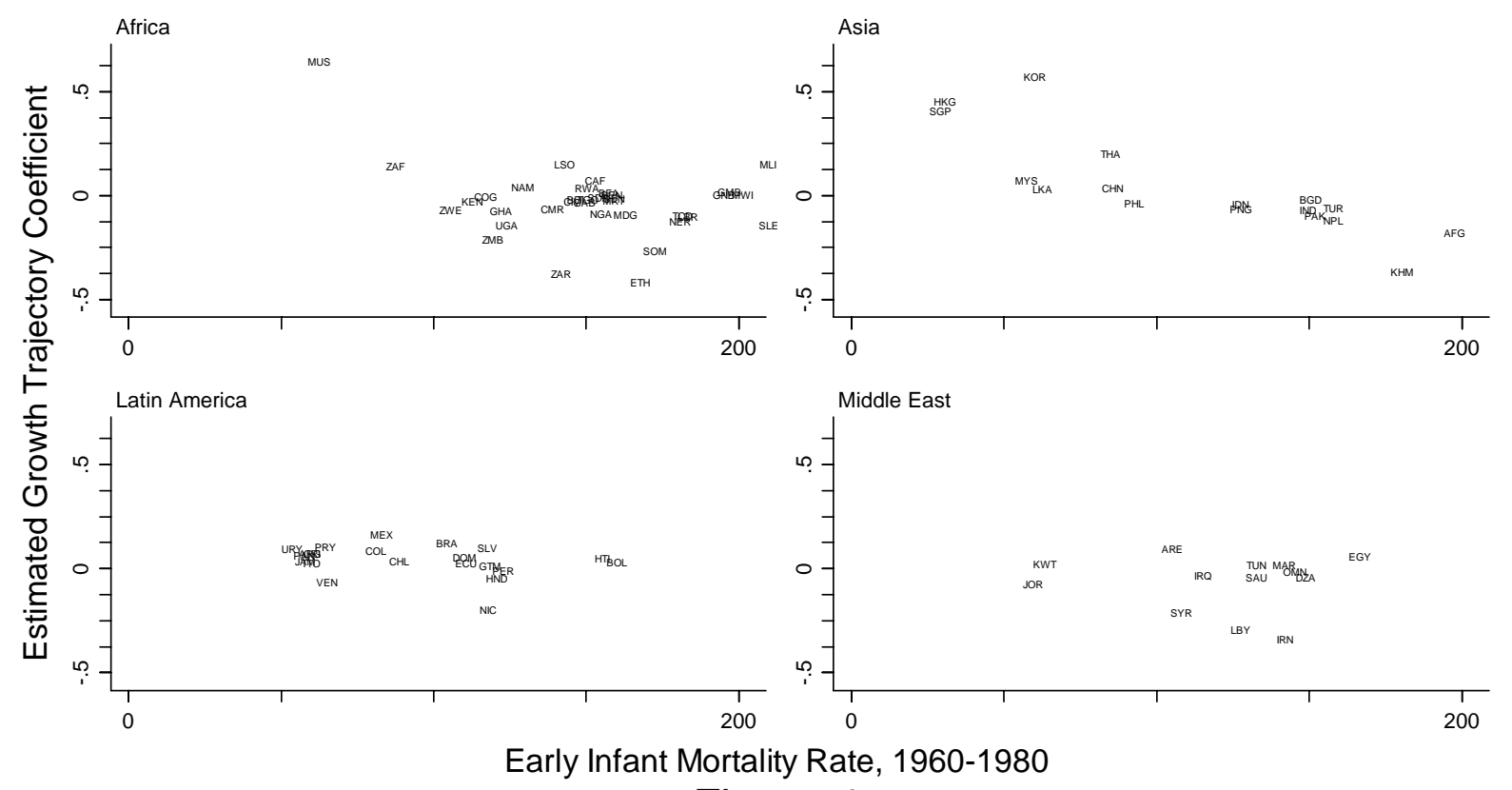

Figure 4

\section{Explaining Growth Trajectories with Early LE}
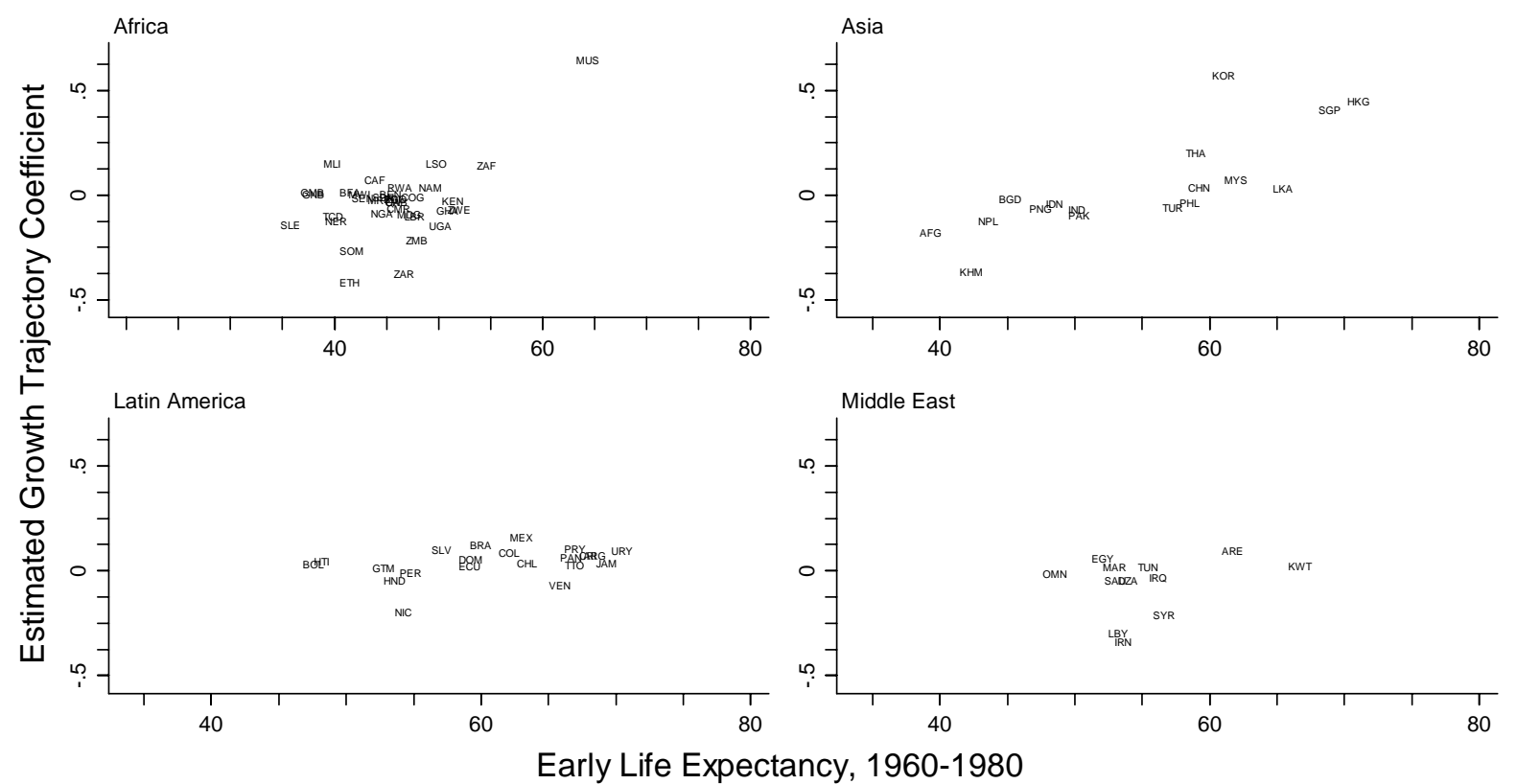

Figure 5 


\section{Explaining Growth Trajectories with Early Secondary Enrollment}
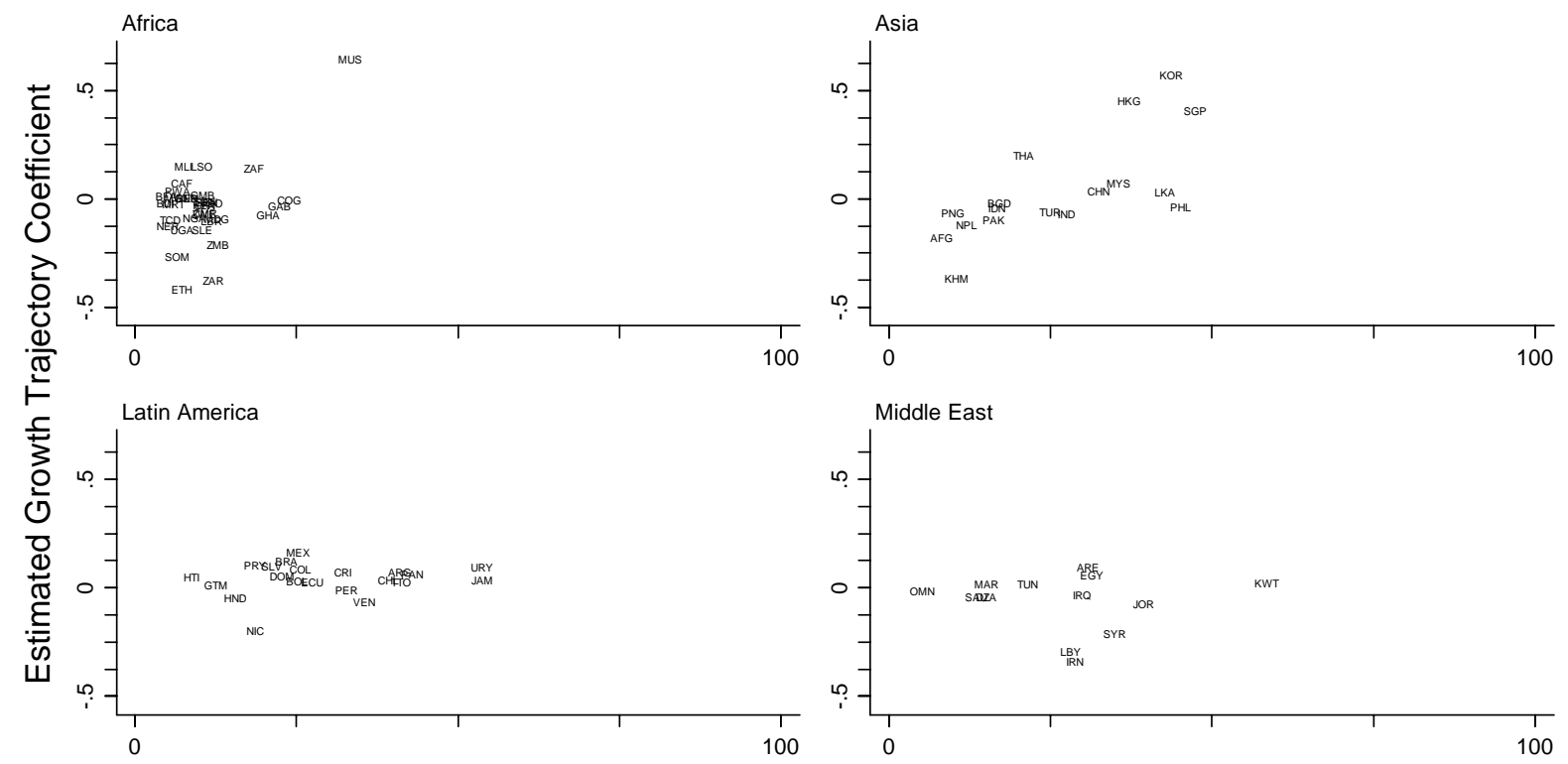

Early Secondary Enrollment, 1960-1980

Figure 6

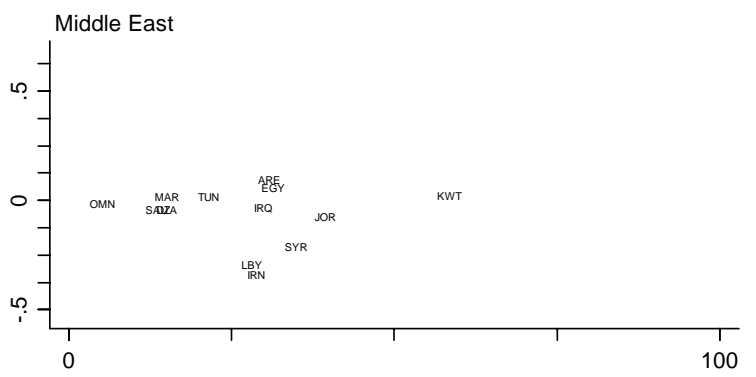

Figure 7

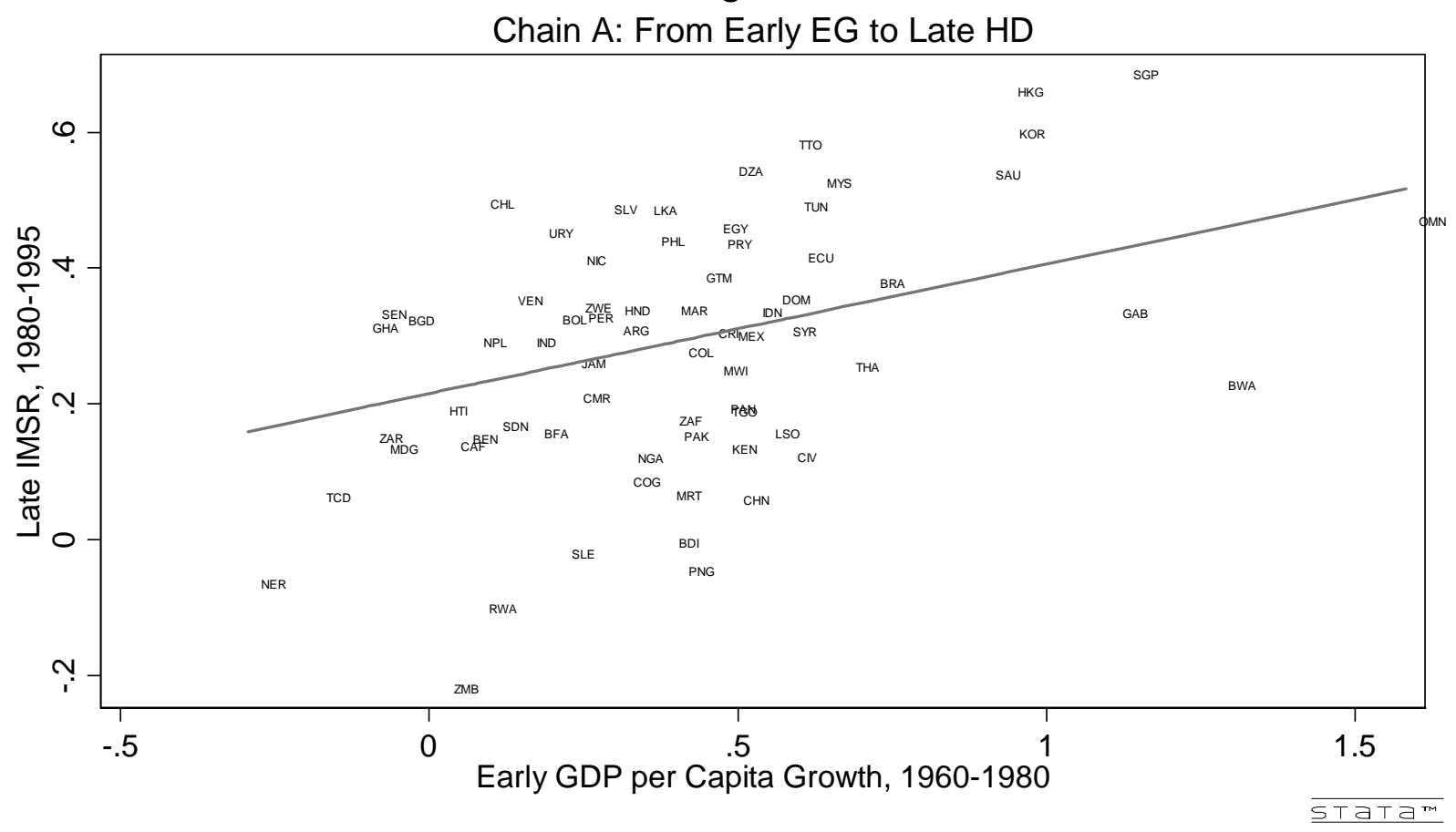


Figure 8

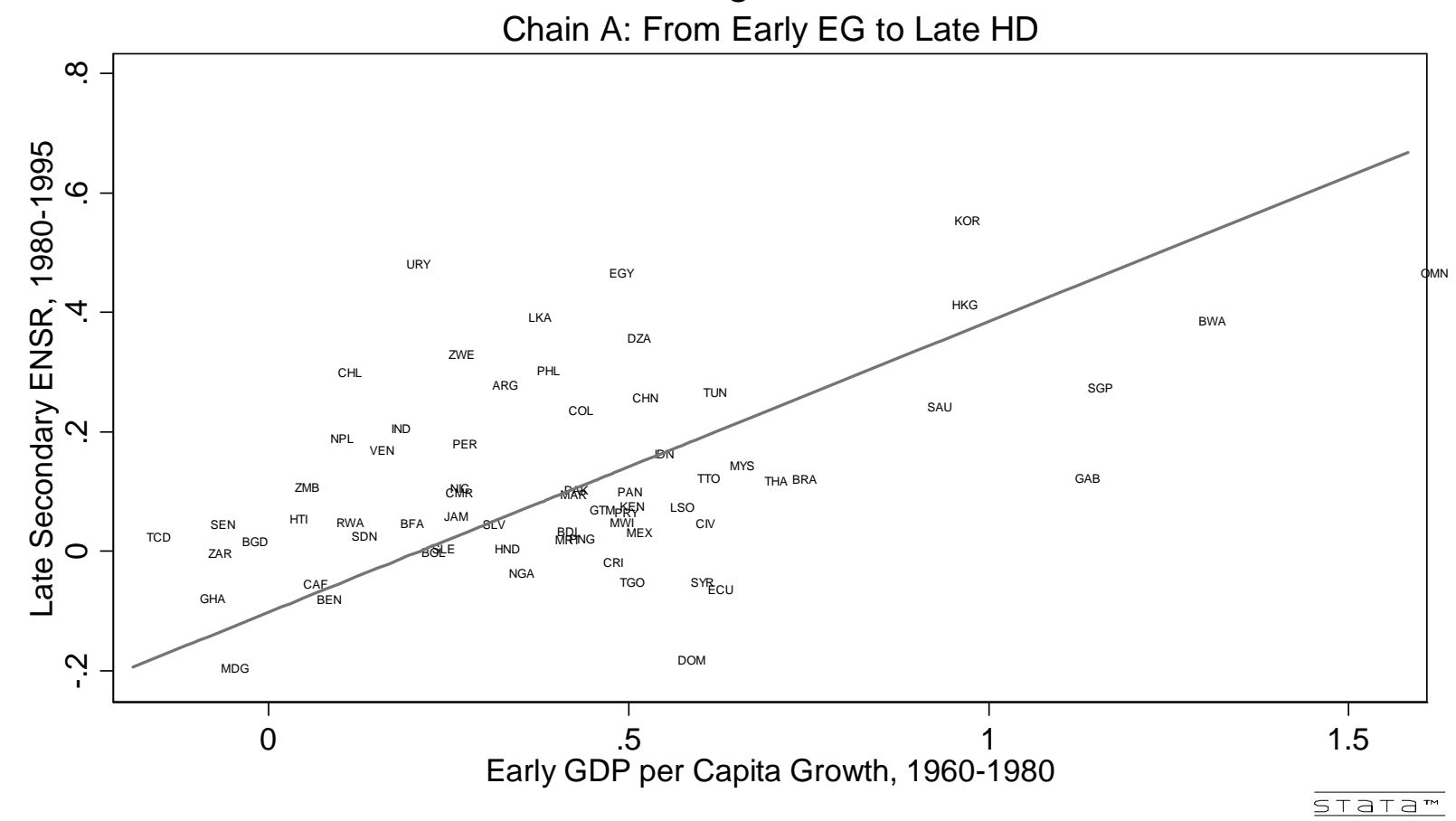

Figure 9

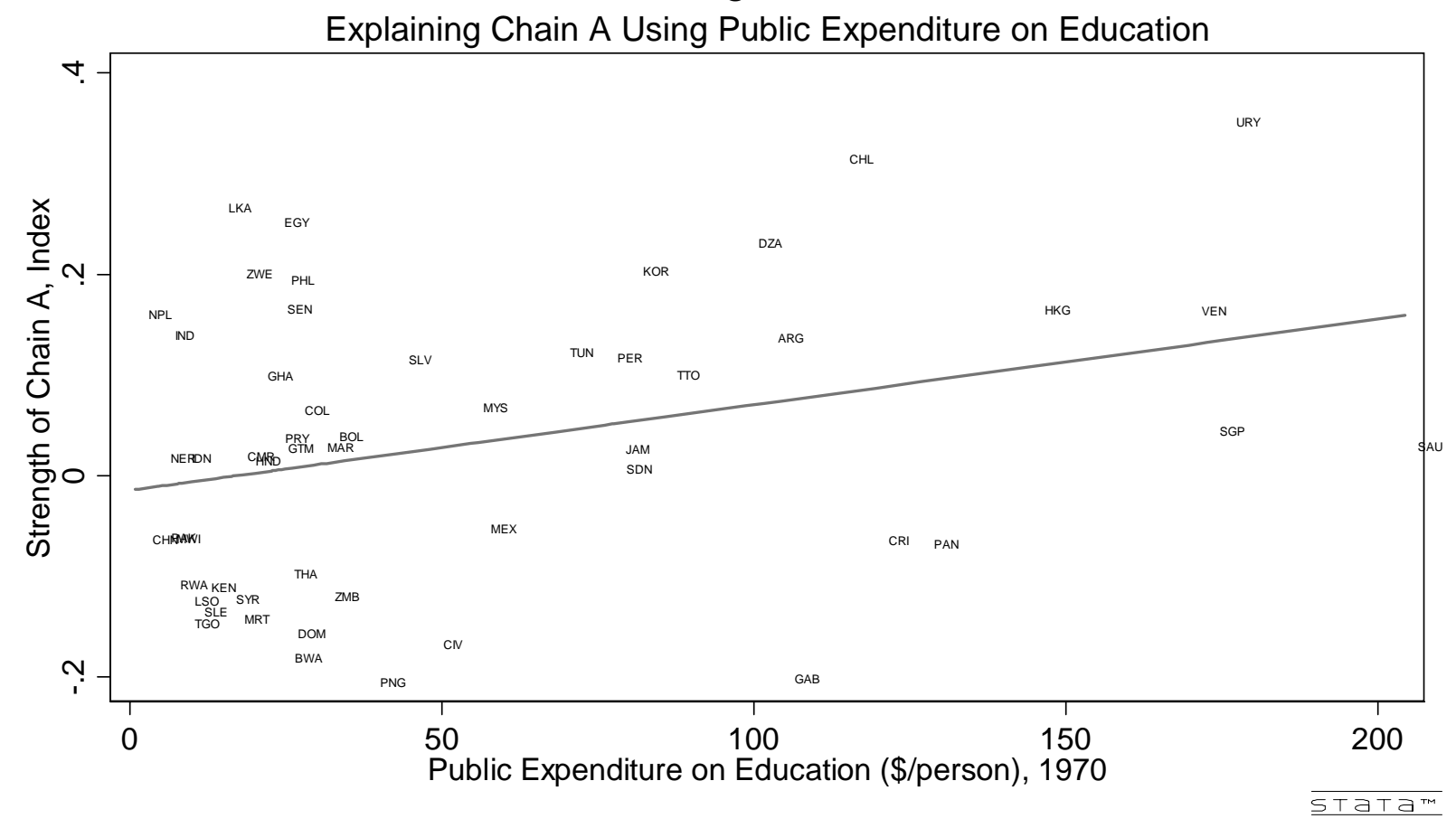


Figure 10

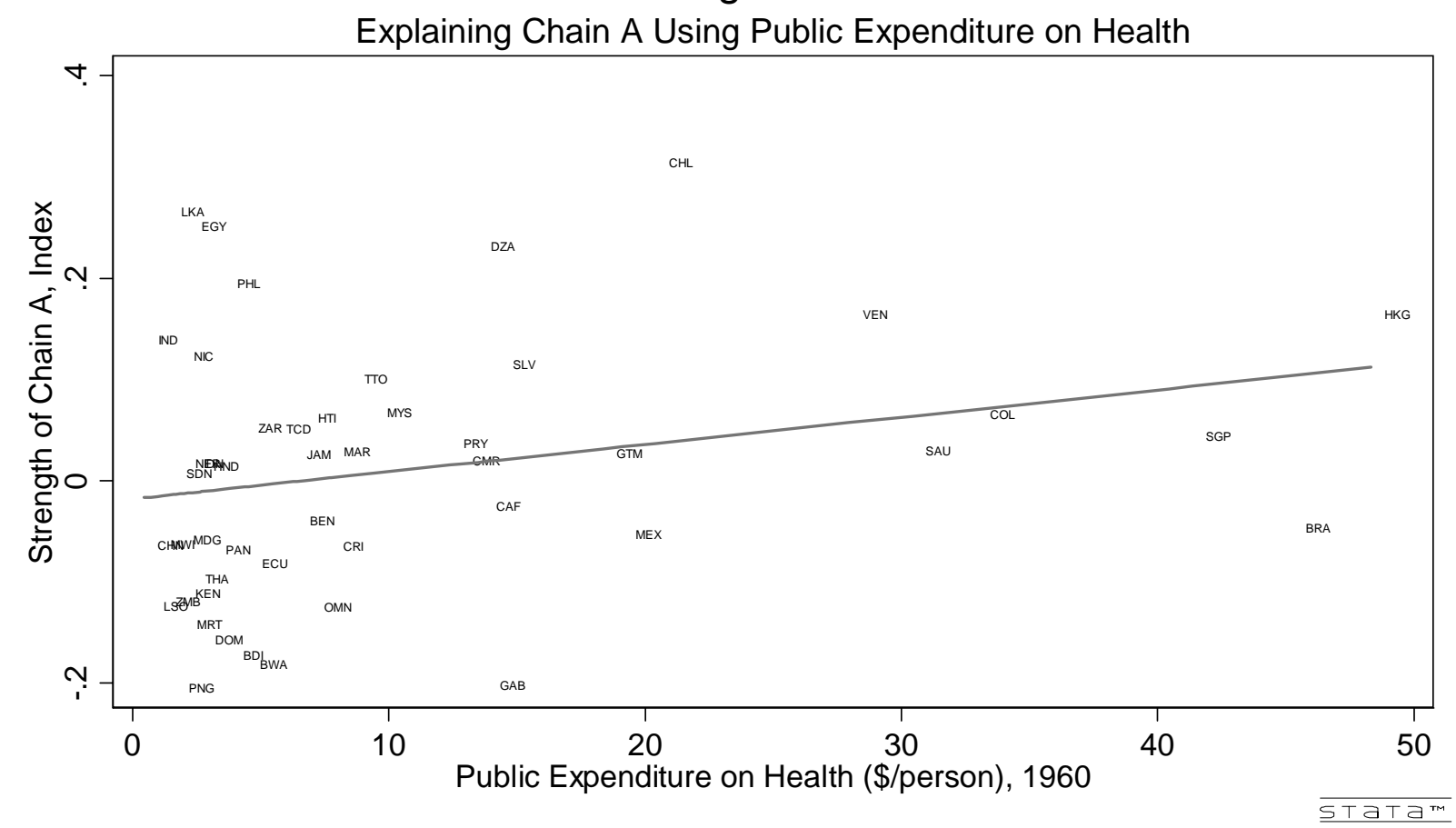

Figure 11

Relation Between Strength of Chain A and Late EG

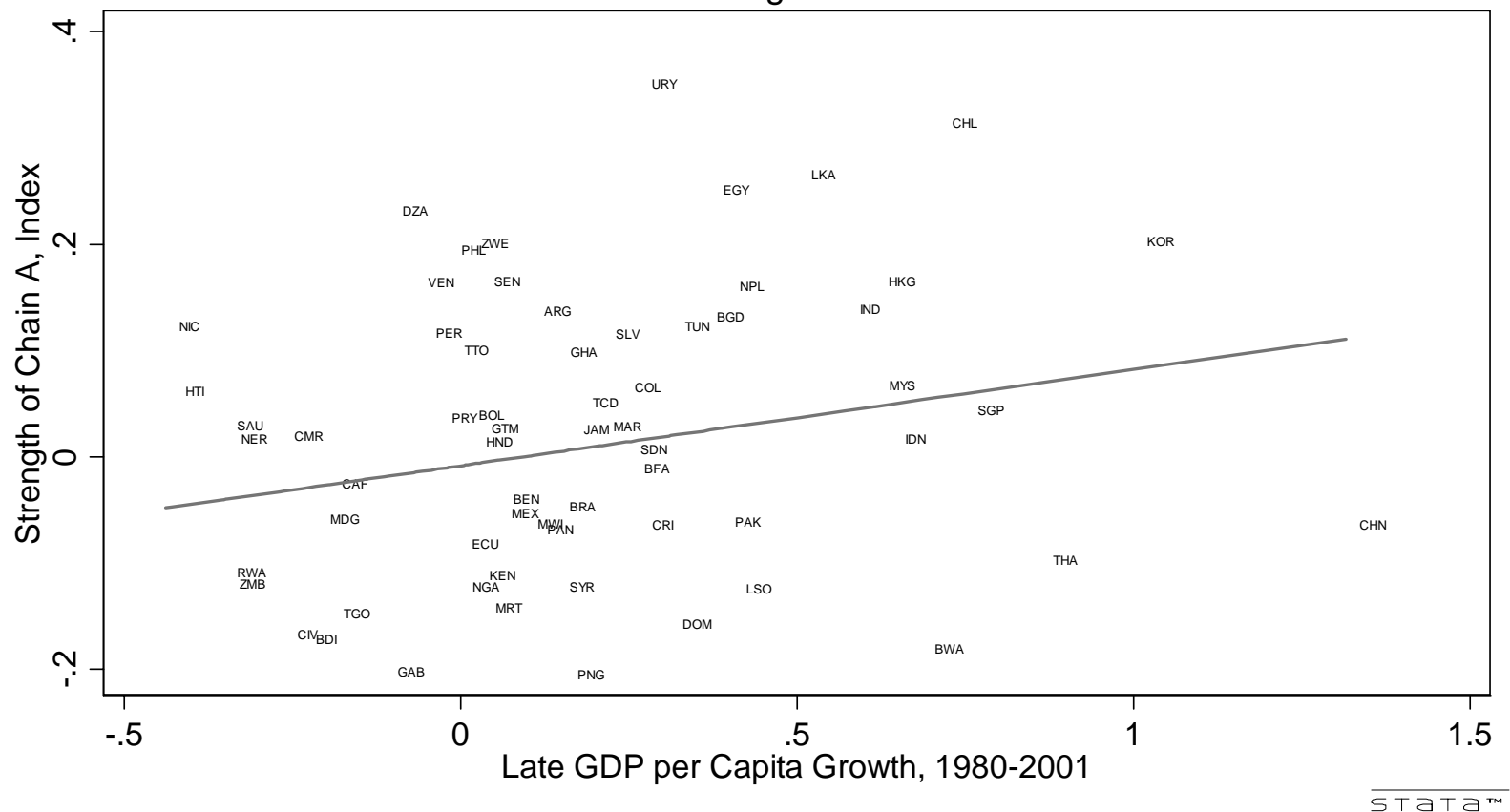


Figure 12

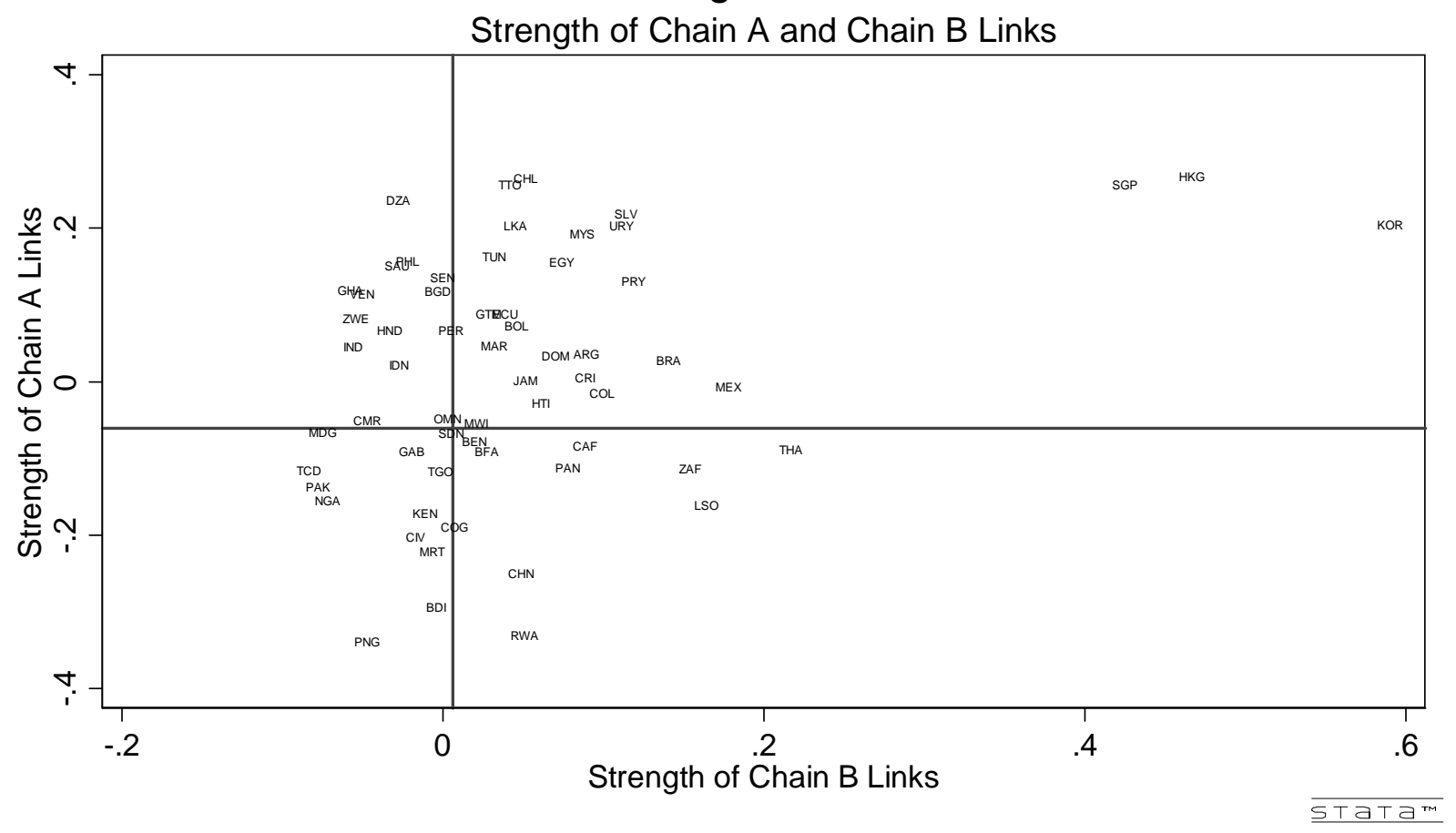

\section{Appendix 1 \\ Country Codes}

\begin{tabular}{|c|c|}
\hline Afghanistan AFG & Egypt EGY \\
\hline Algeria DZA & El Salvador SLV \\
\hline Angola AGO & Eritrea ERI \\
\hline Argentina ARG & Ethiopia ETH \\
\hline Bangladesh BGD & Gabon GAB \\
\hline Benin BEN & Gambia, The GMB \\
\hline Bolivia BOL & Ghana GHA \\
\hline Botswana BWA & Guatemala GTM \\
\hline Brazil BRA & Guinea GIN \\
\hline Burkina Faso BFA & Guinea-Bissau \\
\hline Burundi $\quad$ BDI & Haiti HTI \\
\hline Cambodia KHM & Honduras HND \\
\hline Cameroon CMR & Hong Kong HKG \\
\hline Central African & India IND \\
\hline Republic CAF & Indonesia IDN \\
\hline Chad TCD & Iran, Islamic Rep. \\
\hline Chile CHL & IRN \\
\hline China & Iraq IRQ \\
\hline Colombia COL & Jamaica JAM \\
\hline Congo, DR ZAR & Jordan JOR \\
\hline Congo, Rep. COG & Kenya KEN \\
\hline Costa Rica CRI & Korea, Dem. Rep. \\
\hline Cote d'Ivoire CIV & PRK \\
\hline Cuba CUB & Korea, Rep. KOR \\
\hline Dominican Rep. & Kuwait KWT \\
\hline DOM & Lao PDR LAO \\
\hline Ecuador & Lebanon LBN \\
\hline
\end{tabular}

Lesotho LSO

Liberia LBR

Libya LBY

Madagascar MDG

Malawi MWI

Malaysia MYS

Mali MLI

Mauritania MRT

Mauritius MUS

Mexico MEX

Mongolia MNG

Morocco MAR

Mozambique MOZ

Myanmar MMR

Namibia NAM

Nepal NPL

Niger NER

Nigeria NGA

Oman OMN

Pakistan PAK

Panama PAN

Papua New Guinea

PNG

Paraguay PRY

Peru PER

Philippines PHL

Rwanda RWA
Saudi Arabia SAU

Senegal SEN

Sierra Leone SLE

Singapore SGP

Somalia SOM

South Africa ZAF

Sri Lanka LKA

Sudan SDN

Syrian Arab Rep.

SYR

Tanzania TZA

Thailand THA

Togo TGO

Trinidad \& Tobago

TTO

Tunisia TUN

Turkey TUR

Uganda UGA

UAE ARE

Uruguay URY

Venezuela, RB

VEN

Vietnam VNM

Yemen, Rep. YEM

Zambia ZMB

Zimbabwe ZWE 
Table 1

Virtuous, Vicious and Lop-Sided Performance, 1960-2001

\begin{tabular}{|c|c|c|c|c|}
\hline & $1960-1970$ & 1970-1980 & 1980-1990 & 1990-2001 \\
\hline \multicolumn{5}{|l|}{ Africa } \\
\hline Benin & Vicious & Vicious & Vicious & Vicious \\
\hline Botswana & Virtuous & Virtuous & Virtuous & HD-Lopsided \\
\hline Burkina Faso & Vicious & Vicious & Vicious & Vicious \\
\hline Burundi & EG-Lopsided & Vicious & Vicious & Vicious \\
\hline Cameroon & Vicious & EG-Lopsided & Vicious & Vicious \\
\hline Central African Republic & Vicious & Vicious & Vicious & Vicious \\
\hline Chad & Vicious & Vicious & Vicious & Vicious \\
\hline Congo, Dem. Rep. & Vicious & Vicious & Vicious & Vicious \\
\hline Congo, Rep. & Virtuous & Virtuous & Vicious & Vicious \\
\hline Cote d'Ivoire & EG-Lopsided & Vicious & Vicious & Vicious \\
\hline Ethiopia & - & - & Vicious & Vicious \\
\hline Gabon & EG-Lopsided & EG-Lopsided & Vicious & Vicious \\
\hline Gambia, The & - & Vicious & Vicious & Vicious \\
\hline Ghana & HD-Lopsided & Vicious & Vicious & Vicious \\
\hline Guinea-Bissau & - & Vicious & Vicious & Vicious \\
\hline Kenya & HD-Lopsided & Virtuous & HD-Lopsided & HD-Lopsided \\
\hline Lesotho & EG-Lopsided & EG-Lopsided & Vicious & Vicious \\
\hline Madagascar & Vicious & Vicious & Vicious & Vicious \\
\hline Malawi & EG-Lopsided & EG-Lopsided & Vicious & Vicious \\
\hline Mali & - & Vicious & Vicious & Vicious \\
\hline Mauritania & EG-Lopsided & Vicious & Vicious & Vicious \\
\hline Mauritius & - & - & Virtuous & HD-Lopsided \\
\hline Mozambique & - & - & Vicious & EG-Lopsided \\
\hline Namibia & - & - & Vicious & Vicious \\
\hline Niger & Vicious & Vicious & Vicious & Vicious \\
\hline Nigeria & EG-Lopsided & Vicious & Vicious & Vicious \\
\hline Rwanda & Vicious & Vicious & Vicious & Vicious \\
\hline Senegal & Vicious & Vicious & Vicious & Vicious \\
\hline Sierra Leone & EG-Lopsided & Vicious & Vicious & Vicious \\
\hline South Africa & Virtuous & HD-Lopsided & HD-Lopsided & HD-Lopsided \\
\hline Sudan & Vicious & Vicious & Vicious & EG-Lopsided \\
\hline Togo & EG-Lopsided & Vicious & Vicious & Vicious \\
\hline Zambia & HD-Lopsided & Vicious & Vicious & Vicious \\
\hline Zimbabwe & Virtuous & HD-Lopsided & HD-Lopsided & HD-Lopsided \\
\hline
\end{tabular}




\section{Middle East}

Algeria
Egypt, Arab Rep.
Iran, Islamic Rep.
Jordan
Kuwait
Morocco
Oman
Saudi Arabia
Syrian Arab Republic
Tunisia
United Arab Emirates
East Asia
China
Hong Kong, China
Indonesia
Korea, Rep.
Lao PDR
Malaysia
Mongolia
Papua New Guinea
Philippines
Singapore
Thailand
Turkey
Vietnam

Vietnam

\section{Latin America}

Argentina
Bolivia
Brazil
Chile
Colombia
Costa Rica
Dominican Republic
Ecuador
El Salvador
Guatemala
Haiti
Honduras
Jamaica
Mexico
Nicaragua

$\begin{array}{cccc}\text { Vicious } & \text { EG-Lopsided } & \text { Vicious } & \text { HD-Lopsided } \\ \text { EG-Lopsided } & \text { EG-Lopsided } & \text { Vicious } & \text { Vicious } \\ - & \text { Vicious } & \text { Vicious } & \text { HD-Lopsided } \\ - & - & \text { HD-Lopsided } & \text { HD-Lopsided } \\ \text { HD-Lopsided } & \text { HD-Lopsided } & \text { HD-Lopsided } & \text { HD-Lopsided } \\ \text { EG-Lopsided } & \text { EG-Lopsided } & \text { Vicious } & \text { Vicious } \\ \text { EG-Lopsided } & \text { Vicious } & \text { Virtuous } & - \\ \text { EG-Lopsided } & \text { EG-Lopsided } & \text { HD-Lopsided } & \text { HD-Lopsided } \\ \text { Virtuous } & \text { Virtuous } & \text { HD-Lopsided } & \text { HD-Lopsided } \\ \text { EG-Lopsided } & \text { EG-Lopsided } & \text { HD-Lopsided } & \text { HD-Lopsided } \\ & \text { HD-Lopsided } & \text { HD-Lopsided } & \text { HD-Lopsided }\end{array}$

$\begin{array}{cccc}\text { HD-Lopsided } & \text { Virtuous } & \text { Virtuous } & \text { Virtuous } \\ \text { Virtuous } & \text { Virtuous } & \text { Virtuous } & \text { HD-Lopsided } \\ \text { Virtuous } & \text { EG-Lopsided } & \text { EG-Lopsided } & \text { HD-Lopsided } \\ \text { Virtuous } & \text { Virtuous } & \text { Virtuous } & \text { Virtuous } \\ - & - & \text { Vicious } & \text { Vicious } \\ \text { Virtuous } & \text { Virtuous } & \text { HD-Lopsided } & \text { Virtuous } \\ - & - & \text { Vicious } & \text { Vicious } \\ \text { EG-Lopsided } & \text { Vicious } & \text { HD-Lopsided } & \text { Vicious } \\ \text { Virtuous } & \text { Virtuous } & \text { HD-Lopsided } & \text { HD-Lopsided } \\ \text { Virtuous } & \text { Virtuous } & \text { Virtuous } & \text { Virtuous } \\ \text { Virtuous } & \text { Virtuous } & \text { Virtuous } & \text { HD-Lopsided } \\ - & \text { Vicious } & \text { Vicious } & \text { HD-Lopsided } \\ - & - & \text { HD-Lopsided } & \text { Virtuous }\end{array}$

$\begin{array}{lccc}\text { Virtuous } & \text { HD-Lopsided } & \text { HD-Lopsided } & \text { HD-Lopsided } \\ \text { Vicious } & \text { Vicious } & \text { Vicious } & \text { Vicious } \\ \text { Virtuous } & \text { Virtuous } & \text { HD-Lopsided } & \text { HD-Lopsided } \\ \text { Virtuous } & \text { HD-Lopsided } & \text { HD-Lopsided } & \text { Virtuous } \\ \text { Virtuous } & \text { Virtuous } & \text { HD-Lopsided } & \text { HD-Lopsided } \\ \text { Virtuous } & \text { Virtuous } & \text { HD-Lopsided } & \text { HD-Lopsided } \\ \text { Virtuous } & \text { Virtuous } & \text { HD-Lopsided } & \text { Virtuous } \\ \text { HD-Lopsided } & \text { Virtuous } & \text { HD-Lopsided } & \text { HD-Lopsided } \\ \text { Virtuous } & \text { Vicious } & \text { Vicious } & \text { HD-Lopsided } \\ \text { Virtuous } & \text { EG-Lopsided } & \text { Vicious } & \text { HD-Lopsided } \\ \text { Vicious } & \text { EG-Lopsided } & \text { Vicious } & \text { Vicious } \\ \text { Vicious } & \text { Vicious } & \text { HD-Lopsided } & \text { HD-Lopsided } \\ \text { Virtuous } & \text { HD-Lopsided } & \text { HD-Lopsided } & \text { HD-Lopsided } \\ \text { Virtuous } & \text { Virtuous } & \text { HD-Lopsided } & \text { HD-Lopsided } \\ \text { Virtuous } & \text { HD-Lopsided } & \text { Vicious } & \text { HD-Lopsided }\end{array}$




\begin{tabular}{lcccc} 
Panama & Virtuous & HD-Lopsided & HD-Lopsided & HD-Lopsided \\
Paraguay & Virtuous & Virtuous & HD-Lopsided & HD-Lopsided \\
Peru & Virtuous & Vicious & HD-Lopsided & HD-Lopsided \\
Trinidad and Tobago & Virtuous & Virtuous & HD-Lopsided & HD-Lopsided \\
Uruguay & HD-Lopsided & Virtuous & HD-Lopsided & HD-Lopsided \\
Venezuela, RB & HD-Lopsided & HD-Lopsided & HD-Lopsided & HD-Lopsided \\
& & & & \\
South Asia & & & & \\
Bangladesh & Vicious & Vicious & Vicious & Vicious \\
India & Vicious & Vicious & EG-Lopsided & Vicious \\
Nepal & Vicious & Vicious & Vicious & Vicious \\
Pakistan & EG-Lopsided & Vicious & Vicious & Vicious \\
Sri Lanka & Virtuous & Virtuous & HD-Lopsided & HD-Lopsided \\
& & & & \\
\hline
\end{tabular}

Notes: $\quad$ Data source is the online World Development Indicators (2003).

All classifications of countries into quadrants are based on performance relative to population weighted developing world averages. 
Table 2

Chain A Regressions: From EG to the Change in HD

(Measure of $\triangle H D$ is IMSR, 1960-2001)

\begin{tabular}{|c|c|c|c|c|c|c|c|c|}
\hline Variable & (1) & (2) & (3) & (4) & (5) & (6) & (7) & (8) \\
\hline $\begin{array}{l}\text { GDP per Capita, } 1960 \\
\times 10^{6}\end{array}$ & $\begin{array}{c}4.84 \\
(1.45)\end{array}$ & $\begin{array}{c}4.60 \\
(1.33)\end{array}$ & $\begin{array}{l}4.63 \\
(1.33)\end{array}$ & $\begin{array}{l}30.8 \\
(1.21)\end{array}$ & $\begin{array}{l}22.8 \\
(1.21)\end{array}$ & $\begin{array}{l}3.65 \\
(1.14)\end{array}$ & $\begin{array}{l}-7.13 \\
(0.32)\end{array}$ & $\begin{array}{l}-4.61 \\
(0.21)\end{array}$ \\
\hline $\begin{array}{l}\text { GDP per Capita Growth Rate, 1960-1980 } \\
\text { x } 10\end{array}$ & $\begin{array}{l}1.06 * * \\
(2.07)\end{array}$ & $\begin{array}{l}0.99 * \\
(1.85)\end{array}$ & $\begin{array}{l}1.01^{*} \\
(1.85)\end{array}$ & $\begin{array}{c}1.30 \\
(1.64)\end{array}$ & $\begin{array}{c}0.59 \\
(0.94)\end{array}$ & $\begin{array}{l}1.09 * \\
(1.97)\end{array}$ & $\begin{array}{l}-1.31 \\
(1.58)\end{array}$ & $\begin{array}{l}-1.22 \\
(1.50)\end{array}$ \\
\hline $\begin{array}{l}\text { Gross Primary Enrollment Rate, } 1960 \text { x } \\
1000\end{array}$ & $\begin{array}{l}1.08 * \\
(1.77)\end{array}$ & - & $\begin{array}{c}0.60 \\
(0.29)\end{array}$ & - & - & - & - & $\begin{array}{c}0.86 \\
(1.06)\end{array}$ \\
\hline $\begin{array}{l}\text { Gross Female Primary Enrollment Rate, } \\
1960 \text { x } 1000\end{array}$ & - & $\begin{array}{l}1.04 * \\
(1.73)\end{array}$ & $\begin{array}{c}0.50 \\
(0.26)\end{array}$ & $\begin{array}{l}2.76 * * * \\
(3.14)\end{array}$ & $\begin{array}{c}1.07 \\
(1.46)\end{array}$ & $\begin{array}{l}2.21 * * * \\
(3.24)\end{array}$ & $\begin{array}{c}0.96 \\
(1.31)\end{array}$ & - \\
\hline $\begin{array}{l}\text { Gini Coefficient, average over 1960- } \\
2001 \times 1000\end{array}$ & - & - & - & $\begin{array}{l}-4.89 * \\
(1.83)\end{array}$ & $\begin{array}{c}0.20 \\
(0.09)\end{array}$ & - & - & - \\
\hline $\begin{array}{l}\text { Poverty Headcount, average over 1985- } \\
2001 \text { x } 1000\end{array}$ & - & - & - & - & - & - & $\begin{array}{l}-3.83 * * * \\
(2.93)\end{array}$ & $\begin{array}{l}-3.73 * * * \\
(2.85)\end{array}$ \\
\hline $\begin{array}{l}\text { Public Expenditure on Education ( } \% \text { of } \\
\text { GDP), } 1980-1990 \times 100\end{array}$ & - & - & - & - & - & $\begin{array}{l}1.21 * * * \\
(2.80)\end{array}$ & - & - \\
\hline $\begin{array}{l}\text { Public Expenditure on Health ( } \% \text { of } \\
\text { GNP), } 1960 \times 100\end{array}$ & - & - & - & - & - & $\begin{array}{l}6.13 * * \\
(2.65)\end{array}$ & - & - \\
\hline Middle East Dummy & $\begin{array}{c}0.32 * * * \\
(6.02)\end{array}$ & $\begin{array}{c}0.33 * * * \\
(6.08)\end{array}$ & $\begin{array}{c}0.33 * * * \\
(5.70)\end{array}$ & - & $\begin{array}{c}0.34 * * * \\
(4.96)\end{array}$ & $\begin{array}{c}0.41 * * * \\
(7.53)\end{array}$ & $\begin{array}{c}0.28 * * * \\
(4.21)\end{array}$ & $\begin{array}{c}0.28 * * * \\
(4.20)\end{array}$ \\
\hline Asia Dummy & $\begin{array}{c}0.25 * * * \\
(6.01)\end{array}$ & $\begin{array}{c}0.25^{* * *} * \\
(6.12)\end{array}$ & $\begin{array}{c}0.25 * * * \\
(5.84)\end{array}$ & - & $\begin{array}{c}0.28 * * * \\
(5.64)\end{array}$ & $\begin{array}{c}0.34 * * * \\
(7.30)\end{array}$ & $\begin{array}{c}0.19 * * * \\
(3.98)\end{array}$ & $\begin{array}{c}0.19 * * * \\
(3.93)\end{array}$ \\
\hline
\end{tabular}




\begin{tabular}{|c|c|c|c|c|c|c|c|c|}
\hline Latin America Dummy & $\begin{array}{c}0.24 * * * \\
(6.10)\end{array}$ & $\begin{array}{c}0.24 * * * \\
(5.65)\end{array}$ & $\begin{array}{c}0.24 * * * \\
(5.60)\end{array}$ & - & $\begin{array}{c}0.25 * * * \\
(5.15)\end{array}$ & $\begin{array}{c}0.31 * * * \\
(6.86)\end{array}$ & $\begin{array}{c}0.26 * * * \\
(5.02)\end{array}$ & $\begin{array}{c}0.27 * * * \\
(5.29)\end{array}$ \\
\hline Intercept & $\begin{array}{c}0.35^{* * * *} \\
(10.62)\end{array}$ & $\begin{array}{c}0.36 * * * \\
(12.84)\end{array}$ & $\begin{array}{c}0.35 * * * \\
(8.47)\end{array}$ & $\begin{array}{c}0.61 * * * \\
(5.07)\end{array}$ & $\begin{array}{c}0.33 * * * \\
(3.19)\end{array}$ & $\begin{array}{c}0.10 \\
(1.56)\end{array}$ & $\begin{array}{c}0.58 * * * \\
(7.20)\end{array}$ & $\begin{array}{c}0.57 * * * \\
(6.52)\end{array}$ \\
\hline Number of Observations & 67 & 66 & 66 & 55 & 55 & 43 & 49 & 50 \\
\hline R-squared & 0.72 & 0.72 & 0.72 & 0.44 & 0.73 & 0.83 & 0.74 & 0.74 \\
\hline
\end{tabular}

Notes: Figures in parentheses are absolute t-statistics. Omitted region is Africa.

$*$ indicates significance at the $10 \%$ level, $* *$ at the $5 \%$ level and $* * *$ at the $1 \%$ level.

Note that the Gross Female Primary Enrollment Rate and Ratio of Female to Male Primary Enrollment Rate are highly correlated $(0.76)$. 
Table 3

Chain B Regressions: From HD to EG

(Measure of EG is GDP per Capita Growth, 1960-2001)

\begin{tabular}{|c|c|c|c|c|c|c|c|c|c|}
\hline Variable & (1) & (2) & (3) & (4) & (5) & (6) & (7) & (8) & (9) \\
\hline Log GDP per Capita, $1960 \times 10$ & $\begin{array}{l}-2.80 * * * \\
(3.42)\end{array}$ & $\begin{array}{l}-2.64 * * * \\
(3.04)\end{array}$ & $\begin{array}{l}-3.32 * * * \\
(3.80)\end{array}$ & $\begin{array}{l}-1.54 \\
(1.62)\end{array}$ & $\begin{array}{l}-2.33 * * \\
(2.38)\end{array}$ & $\begin{array}{c}-2.86 * * * \\
(3.43)\end{array}$ & $\begin{array}{l}-2.91 * * * \\
(3.66)\end{array}$ & $\begin{array}{c}-2.63 * * * \\
(3.27)\end{array}$ & $\begin{array}{c}-2.96 * * * \\
(3.81)\end{array}$ \\
\hline Literacy Rate, 1970-1975 x100 & $\begin{array}{c}1.95 * * * \\
(4.88)\end{array}$ & - & $\begin{array}{l}1.29 * * \\
(2.25)\end{array}$ & $\begin{array}{l}0.98 * * \\
(2.12)\end{array}$ & - & - & $\begin{array}{c}0.95 \\
(1.61)\end{array}$ & - & - \\
\hline $\begin{array}{l}\text { Literacy Shortfall Reduction, 1970- } \\
1980\end{array}$ & - & - & - & - & - & - & $\begin{array}{l}4.97 * * \\
(2.22)\end{array}$ & $\begin{array}{c}4.21 * * * \\
(2.74)\end{array}$ & $\begin{array}{c}1.94 \\
(1.53)\end{array}$ \\
\hline Log Life Expectancy, 1960 & - & $\begin{array}{c}2.67 * * * \\
(4.31)\end{array}$ & $\begin{array}{l}1.43 \\
(1.59)\end{array}$ & - & $\begin{array}{c}1.81 * * * \\
(2.93)\end{array}$ & $\begin{array}{l}2.27 * * * \\
(3.71)\end{array}$ & - & - & - \\
\hline $\begin{array}{l}\text { Life Expectancy Shortfall Reduction, } \\
1960-1980\end{array}$ & - & - & - & - & - & $\begin{array}{l}2.21 * * * \\
(2.71)\end{array}$ & - & - & - \\
\hline $\begin{array}{l}\text { Gross Domestic Investment (\% of } \\
\text { GDP), average over } 1960-2001 \times 100\end{array}$ & - & - & - & $\begin{array}{l}5.81 * * * \\
(3.71)\end{array}$ & $\begin{array}{l}5.57 * * * \\
(4.36)\end{array}$ & - & - & $\begin{array}{l}5.04 * * * \\
(3.60)\end{array}$ & $\begin{array}{l}2.80 * * \\
(2.39)\end{array}$ \\
\hline $\begin{array}{l}\text { Exports (\% of GDP), average over } \\
1960-2001 \times 1000\end{array}$ & - & - & - & - & - & - & - & $\begin{array}{c}3.76 \\
(1.14)\end{array}$ & $\begin{array}{l}1.80 \\
(0.42)\end{array}$ \\
\hline $\begin{array}{l}\text { Gini coefficient, average over } 1960 \text { - } \\
2001 \times 1000\end{array}$ & - & - & - & $\begin{array}{l}-1.61 \\
(0.18)\end{array}$ & $\begin{array}{c}3.46 \\
(0.41)\end{array}$ & - & - & - & - \\
\hline $\begin{array}{l}\text { Poverty Headcount, average over } \\
1985-2001 \times 1000\end{array}$ & - & - & - & - & - & - & - & - & $\begin{array}{c}-16.4 * * * \\
(4.94)\end{array}$ \\
\hline Middle East Dummy & $\begin{array}{c}0.65 * * * \\
(2.64)\end{array}$ & $\begin{array}{c}0.17 \\
(0.68)\end{array}$ & $\begin{array}{l}0.48 * \\
(1.84)\end{array}$ & $\begin{array}{l}0.25 \\
(0.80)\end{array}$ & $\begin{array}{c}0.05 \\
(0.19)\end{array}$ & $\begin{array}{l}-0.06 \\
(0.25)\end{array}$ & $\begin{array}{l}0.57 * * \\
(2.40)\end{array}$ & $\begin{array}{c}0.29 \\
(1.30)\end{array}$ & $\begin{array}{c}0.21 \\
(1.00)\end{array}$ \\
\hline
\end{tabular}




\begin{tabular}{|c|c|c|c|c|c|c|c|c|c|}
\hline Asia Dummy & $\begin{array}{c}0.66 * * * \\
(3.41)\end{array}$ & $\begin{array}{c}0.63 * * * \\
(3.06)\end{array}$ & $\begin{array}{c}0.59 * * * \\
(2.95)\end{array}$ & $\begin{array}{c}0.46 * * \\
(2.25)\end{array}$ & $\begin{array}{c}0.45 * * \\
(2.33)\end{array}$ & $\begin{array}{l}0.40^{*} \\
(1.86)\end{array}$ & $\begin{array}{c}0.63 * * * \\
(3.36)\end{array}$ & $\begin{array}{c}0.56 * * * \\
(3.37)\end{array}$ & $\begin{array}{c}0.42 * * * \\
(3.14)\end{array}$ \\
\hline Latin America Dummy & $\begin{array}{l}-0.12 \\
(0.61)\end{array}$ & $\begin{array}{l}-0.21 \\
(0.94)\end{array}$ & $\begin{array}{l}-0.22 \\
(1.02)\end{array}$ & $\begin{array}{l}-0.13 \\
(0.62)\end{array}$ & $\begin{array}{l}-0.15 \\
(0.77)\end{array}$ & $\begin{array}{l}-0.30 \\
(1.43)\end{array}$ & $\begin{array}{c}0.03 \\
(0.13)\end{array}$ & $\begin{array}{c}0.28 \\
(1.62)\end{array}$ & $\begin{array}{c}0.36 * * \\
(2.40)\end{array}$ \\
\hline Intercept & $\begin{array}{c}1.19 * * * \\
(2.71)\end{array}$ & $\begin{array}{c}-8.18 * * * \\
(4.01)\end{array}$ & $\begin{array}{l}-3.62 \\
(1.18)\end{array}$ & $\begin{array}{l}-0.14 \\
(0.23)\end{array}$ & $\begin{array}{c}-6.28 * * * \\
(3.07)\end{array}$ & $\begin{array}{c}-6.89 * * * \\
(3.44)\end{array}$ & $\begin{array}{c}1.19 * * * \\
(2.80)\end{array}$ & $\begin{array}{c}0.40 \\
(0.80)\end{array}$ & $\begin{array}{c}1.89 * * * \\
(3.77)\end{array}$ \\
\hline Number of Observations & 67 & 69 & 67 & 55 & 57 & 69 & 67 & 67 & 50 \\
\hline R-squared & 0.52 & 0.48 & 0.54 & 0.64 & 0.67 & 0.54 & 0.56 & 0.66 & 0.79 \\
\hline
\end{tabular}

Notes: Figures in parentheses are absolute t-statistics. For region, the base group is Africa.

$*$ indicates significance at the $10 \%$ level, ** at the $5 \%$ level and *** at the $1 \%$ level.

Note that the Log of Life Expectancy and the Poverty Headcount are highly correlated (-0.59) and that the Poverty Headcount and the Gross Female Primary Enrollment Rate are correlated (-0.51). Also, the Literacy Rate and the Literacy SR are highly correlated (0.83).

All data from the online WDI (2003) except public expenditure on health (from HDR 2001). 
Table 4

Using HD Levels and Changes to Explain the Growth Trajectory Across Countries

(Dependent Variable is the Estimated Growth Trajectory Coefficient)

HD Levels and Changes are for the Period 1960-1980

\begin{tabular}{|c|c|c|c|c|c|c|c|c|c|c|c|c|}
\hline Variable & (1) & (2) & (3) & (4) & (5) & (6) & (7) & (8) & (9) & (10) & (11) & (12) \\
\hline $\begin{array}{l}\text { Infant Mortality, 1960- } \\
1980 \text { x } 1000\end{array}$ & $\begin{array}{c}-2.19 * * * \\
(3.58)\end{array}$ & - & - & $\begin{array}{c}- \\
2.53 * * * \\
(4.37)\end{array}$ & - & - & - & - & - & - & - & - \\
\hline IMSR, 1960-1980 x 10 & - & - & - & - & - & - & $\begin{array}{c}2.95 * * \\
(2.46)\end{array}$ & & & $\begin{array}{l}3.73 * * \\
(2.10)\end{array}$ & - & - \\
\hline $\begin{array}{l}\text { Life Expectancy, 1960- } \\
1980 \text { x } 100\end{array}$ & - & $\begin{array}{c}1.39 * * * \\
(4.15)\end{array}$ & - & - & $\begin{array}{c}1.48 * * * \\
(4.82)\end{array}$ & - & - & - & - & - & - & - \\
\hline LESR, 1960-1980 x 10 & - & - & - & - & - & - & - & $\begin{array}{c}6.27 * * * \\
(2.94)\end{array}$ & - & - & $\begin{array}{c}7.56 * * * \\
(2.68)\end{array}$ & - \\
\hline $\begin{array}{l}\text { Gross Secondary } \\
\text { Enrollment Ratio, 1960- } \\
1980 \text { x } 1000\end{array}$ & - & - & $\begin{array}{c}3.42 \\
(1.62)\end{array}$ & - & - & $\begin{array}{l}4.27 * * \\
(2.13)\end{array}$ & - & - & - & - & - & - \\
\hline $\begin{array}{l}\text { Secondary Enrollment } \\
\text { SR, 1960-1980 x } 10\end{array}$ & - & - & - & - & - & - & - & - & $\begin{array}{l}-0.01 \\
(0.00)\end{array}$ & - & - & $\begin{array}{l}3.32 * \\
(1.74)\end{array}$ \\
\hline $\begin{array}{l}\text { Investment/GDP, 1960- } \\
1980 \times 1000\end{array}$ & $\begin{array}{c}2.39 \\
(0.72)\end{array}$ & $\begin{array}{c}2.51 \\
(0.76)\end{array}$ & $\begin{array}{c}3.81 \\
(1.07)\end{array}$ & - & - & - & $\begin{array}{c}4.71 \\
(1.35)\end{array}$ & $\begin{array}{c}4.26 \\
(1.24)\end{array}$ & $\begin{array}{l}8.14^{*} \\
(1.92)\end{array}$ & - & - & - \\
\hline $\begin{array}{l}\text { Change in Investment } \\
\text { Ratio, 1960-1980 x } 100\end{array}$ & - & - & - & $\begin{array}{c}8.79 * * * \\
(3.55)\end{array}$ & $\begin{array}{c}8.50 * * * \\
(3.53)\end{array}$ & $\begin{array}{l}9.15 * * * \\
(3.25)\end{array}$ & - & - & - & $\begin{array}{c}8.75 * * * \\
(3.14)\end{array}$ & $\begin{array}{c}7.91 * * * \\
(2.93)\end{array}$ & $\begin{array}{c}9.76 * * * \\
(3.27)\end{array}$ \\
\hline $\begin{array}{l}\text { Exports/GDP, 1960- } \\
1980 \times 1000\end{array}$ & $\begin{array}{c}0.74 \\
(0.65)\end{array}$ & $\begin{array}{c}0.54 \\
(0.48)\end{array}$ & $\begin{array}{l}1.78 \\
(1.54)\end{array}$ & - & - & - & $\begin{array}{c}1.26 \\
(1.07)\end{array}$ & $\begin{array}{c}1.27 \\
(1.12)\end{array}$ & $\begin{array}{c}1.77 \\
(1.46)\end{array}$ & - & - & - \\
\hline $\begin{array}{l}\text { Change in Export Ratio, } \\
1960-1980 \times 100\end{array}$ & - & - & - & $\begin{array}{l}5.17 * * \\
(2.02)\end{array}$ & $\begin{array}{l}5.50 * * \\
(2.21)\end{array}$ & $\begin{array}{c}4.32 \\
(1.51)\end{array}$ & - & - & - & $\begin{array}{c}3.05 \\
(1.02)\end{array}$ & $\begin{array}{c}3.93 \\
(1.39)\end{array}$ & $\begin{array}{l}5.13 * \\
(1.70)\end{array}$ \\
\hline
\end{tabular}




\begin{tabular}{|c|c|c|c|c|c|c|c|c|c|c|c|c|}
\hline $\begin{array}{l}\text { Middle East } \\
\text { x } 10\end{array}$ & $\begin{array}{c}-1.57 * * \\
(2.59)\end{array}$ & $\begin{array}{c}-2.28 * * * \\
(3.54)\end{array}$ & $\begin{array}{c}-1.82 * * * \\
(2.66)\end{array}$ & $\begin{array}{l}-0.71 \\
(1.20)\end{array}$ & $\begin{array}{c}-1.65 * * \\
(2.57)\end{array}$ & $\begin{array}{l}-0.94 \\
(1.28)\end{array}$ & $\begin{array}{c}-1.85 * * * \\
(2.74)\end{array}$ & $\begin{array}{c}-2.20 * * * \\
(3.17)\end{array}$ & $\begin{array}{c}-1.75 * * \\
(2.28)\end{array}$ & $\begin{array}{l}-0.97 \\
(1.31)\end{array}$ & $\begin{array}{l}-1.39 * \\
(1.80)\end{array}$ & $\begin{array}{l}-0.67 \\
(0.91)\end{array}$ \\
\hline $\begin{array}{l}\text { Asia } \\
\times 10\end{array}$ & $\begin{array}{l}-0.47 \\
(0.86)\end{array}$ & $\begin{array}{l}-0.91 \\
(1.59)\end{array}$ & $\begin{array}{l}-0.23 \\
(0.36)\end{array}$ & $\begin{array}{l}-0.06 \\
(0.09)\end{array}$ & $\begin{array}{l}-0.17 \\
(0.27)\end{array}$ & $\begin{array}{c}0.58 \\
(0.81)\end{array}$ & $\begin{array}{l}-0.04 \\
(0.07)\end{array}$ & $\begin{array}{l}-0.33 \\
(0.58)\end{array}$ & $\begin{array}{c}0.36 \\
(0.58)\end{array}$ & $\begin{array}{c}0.74 \\
(1.06)\end{array}$ & $\begin{array}{c}0.40 \\
(0.55)\end{array}$ & $\begin{array}{c}0.87 \\
(1.20)\end{array}$ \\
\hline $\begin{array}{l}\text { Latin America } \\
\text { x } 10\end{array}$ & $\begin{array}{l}-0.93 \\
(1.54)\end{array}$ & $\begin{array}{c}-1.86 * * \\
(2.62)\end{array}$ & $\begin{array}{l}-0.30 \\
(0.47)\end{array}$ & $\begin{array}{l}-0.36 \\
(0.66)\end{array}$ & $\begin{array}{l}-1.27 * \\
(1.98)\end{array}$ & $\begin{array}{c}0.25 \\
(0.41)\end{array}$ & $\begin{array}{l}-0.10 \\
(0.18)\end{array}$ & $\begin{array}{l}-0.44 \\
(0.77)\end{array}$ & $\begin{array}{c}0.09 \\
(0.14)\end{array}$ & $\begin{array}{c}0.54 \\
(0.99)\end{array}$ & $\begin{array}{c}0.12 \\
(0.20)\end{array}$ & $\begin{array}{c}0.71 \\
(1.24)\end{array}$ \\
\hline $\begin{array}{l}\text { Constant } \\
\text { x } 10\end{array}$ & $\begin{array}{l}2.53 * \\
(1.98)\end{array}$ & $\begin{array}{c}-6.63 * * * \\
(4.84)\end{array}$ & $\begin{array}{c}-1.33 * * \\
(2.04)\end{array}$ & $\begin{array}{c}2.47 * * * \\
(2.85)\end{array}$ & $\begin{array}{c}-7.60 * * * \\
(5.39)\end{array}$ & $\begin{array}{c}-1.36 * * * \\
(3.22)\end{array}$ & $\begin{array}{c}-1.77 * * * \\
(2.72)\end{array}$ & $\begin{array}{c}-2.00 * * * \\
(3.05)\end{array}$ & $\begin{array}{c}-1.73 * * \\
(2.36)\end{array}$ & $\begin{array}{c}-1.83 * * * \\
(3.31)\end{array}$ & $\begin{array}{c}-2.13 * * * \\
(3.76)\end{array}$ & $\begin{array}{c}-1.56 * * * \\
(3.06)\end{array}$ \\
\hline No of Observations & 81 & 80 & 81 & 62 & 62 & 62 & 80 & 80 & 73 & 62 & 62 & 58 \\
\hline R-squared & 0.28 & 0.32 & 0.19 & 0.45 & 0.48 & 0.32 & 0.22 & 0.25 & 0.19 & 0.32 & 0.35 & 0.33 \\
\hline
\end{tabular}

Notes: Figures in parentheses are absolute t-statistics. For region, the base group is Africa.

* indicates significance at the $10 \%$ level, $* *$ at the $5 \%$ level and *** at the $1 \%$ level. 
Table 5

Explaining the Strength of Chain A Across Countries With Policy

(Dependent Variable is the Estimated Strength of Chain A, as Measured by the Index)

\begin{tabular}{|c|c|c|c|c|c|c|c|c|c|c|c|c|}
\hline Variable & (1) & (2) & (3) & (4) & (5) & (6) & (7) & (8) & (9) & (10) & (11) & (12) \\
\hline $\begin{array}{l}\text { Public Expenditure on Education } \\
\text { (\$/person), } 1970 \times 10000\end{array}$ & $\begin{array}{l}8.50 * * \\
(2.38)\end{array}$ & $\begin{array}{c}5.27 \\
(1.39)\end{array}$ & $\begin{array}{l}11.11 * * \\
(2.40)\end{array}$ & $\begin{array}{l}12.02 * * \\
(2.48)\end{array}$ & $\begin{array}{l}11.51 \\
(1.41)\end{array}$ & $\begin{array}{l}-2.68 \\
(0.31)\end{array}$ & - & - & $\begin{array}{c}3.84 \\
(0.64)\end{array}$ & $\begin{array}{c}1.34 \\
(0.23)\end{array}$ & - & - \\
\hline $\begin{array}{l}\text { Public Expenditure on Health), } \\
1960 \times 1000\end{array}$ & - & - & - & - & - & - & $\begin{array}{l}2.69 * \\
(1.81)\end{array}$ & $\begin{array}{c}1.48 \\
(1.00)\end{array}$ & $\begin{array}{l}4.47 * \\
(1.97)\end{array}$ & $\begin{array}{c}3.49 \\
(1.61)\end{array}$ & $\begin{array}{l}3.54 * * \\
(2.23)\end{array}$ & $\begin{array}{c}2.21 \\
(1.41)\end{array}$ \\
\hline $\begin{array}{l}\text { Priority Ratio: } \% \text { of Public } \\
\text { Expenditure Education Spent on } \\
\text { Pre-Primary and Primary x } 1000\end{array}$ & - & - & $\begin{array}{c}2.46 \\
(1.24)\end{array}$ & - & - & - & - & - & $\begin{array}{l}4.72 * \\
(2.04)\end{array}$ & $\begin{array}{l}4.41 * \\
(2.02)\end{array}$ & - & - \\
\hline $\begin{array}{l}\text { Priority Ratio: } \% \text { of Public } \\
\text { Expenditure Education Spent on } \\
\text { Secondary x } 1000\end{array}$ & - & - & - & $\begin{array}{l}-2.90 \\
(1.15)\end{array}$ & - & - & - & - & - & - & & \\
\hline $\begin{array}{l}\text { Priority Ratio: \% of Public } \\
\text { Expenditure Education Spent on } \\
\text { Pre-Primary, Primary and } \\
\text { Secondary }\end{array}$ & - & - & - & - & - & - & - & - & - & - & & \\
\hline $\begin{array}{l}\text { Gini Coefficient, Average over } \\
1960-2001 \text { x } 1000\end{array}$ & - & - & - & - & $\begin{array}{l}-7.25 * * * \\
(2.67)\end{array}$ & $\begin{array}{c}-7.38 * * \\
(2.43)\end{array}$ & - & - & - & - & $\begin{array}{l}-6.46 * * \\
(2.64)\end{array}$ & $\begin{array}{l}-4.19 \\
(1.55)\end{array}$ \\
\hline Middle East x 10 & - & $\begin{array}{l}1.23 * \\
(1.92)\end{array}$ & $\begin{array}{c}0.80 \\
(1.05)\end{array}$ & $\begin{array}{c}0.96 \\
(1.22)\end{array}$ & - & $\begin{array}{c}1.28 \\
(1.47)\end{array}$ & - & $\begin{array}{c}1.41 * * \\
(2.32)\end{array}$ & - & $\begin{array}{c}1.60 \\
(1.49)\end{array}$ & - & $\begin{array}{c}2.01 * * \\
(2.46)\end{array}$ \\
\hline Asia $\times 10$ & - & $\begin{array}{l}1.12 * * \\
(2.32)\end{array}$ & $\begin{array}{c}1.27 * * \\
(2.41)\end{array}$ & $\begin{array}{l}1.23 * * \\
(2.33)\end{array}$ & - & $\begin{array}{c}1.17 * * \\
(2.30)\end{array}$ & - & $\begin{array}{l}1.12 * * \\
(2.33)\end{array}$ & - & $\begin{array}{c}1.39 * * \\
(2.31)\end{array}$ & - & $\begin{array}{l}1.00 * \\
(1.85)\end{array}$ \\
\hline Latin America x 10 & - & $\begin{array}{l}1.00 * \\
(2.07)\end{array}$ & $\begin{array}{c}0.84 \\
(1.53)\end{array}$ & $\begin{array}{c}0.69 \\
(1.21)\end{array}$ & - & $\begin{array}{c}1.72 * * * \\
(3.38)\end{array}$ & - & $\begin{array}{l}0.89 * \\
(2.08)\end{array}$ & - & $\begin{array}{l}1.07 * \\
(1.89)\end{array}$ & - & $\begin{array}{l}1.06 * * \\
(2.24)\end{array}$ \\
\hline Constant x 100 & $\begin{array}{l}-1.44 \\
(0.55)\end{array}$ & $\begin{array}{c}-7.14^{* *} \\
(2.17)\end{array}$ & $\begin{array}{c}-2.09 * * \\
(2.28)\end{array}$ & $\begin{array}{l}-2.47 \\
(0.32)\end{array}$ & $\begin{array}{c}33.14 * * \\
(2.61)\end{array}$ & $\begin{array}{l}27.41 * \\
(1.84)\end{array}$ & $\begin{array}{l}-0.18 \\
(0.77)\end{array}$ & $\begin{array}{c}-0.75^{* *} \\
(2.51)\end{array}$ & $\begin{array}{c}-2.62 * * \\
(2.46)\end{array}$ & $\begin{array}{c}-3.18 * * * \\
(3.11)\end{array}$ & $\begin{array}{c}2.72 * * \\
(2.43)\end{array}$ & $\begin{array}{c}1.02 \\
(0.77)\end{array}$ \\
\hline
\end{tabular}




\begin{tabular}{|c|c|c|c|c|c|c|c|c|c|c|c|c|}
\hline No. of Observations & 53 & 53 & 38 & 38 & 36 & 36 & 48 & 48 & 24 & 24 & 40 & 40 \\
\hline R-squared & 0.10 & 0.22 & 0.39 & 0.38 & 0.23 & 0.47 & 0.10 & 0.22 & 0.36 & 0.54 & 0.21 & 0.37 \\
\hline
\end{tabular}

Notes: Figures in parentheses are absolute t-statistics. For region, the base group is Africa.

$*$ indicates significance at the $5 \%$ level, $* *$ at the $10 \%$ level and $* * *$ at the $15 \%$ level.

Note that the Public Expenditure on Education, 1970 and Public Expenditure on Health, 1960 are very highly correlated, on the order of 07. 